P\&T 22866

\title{
Exosomes: Therapy delivery tools and biomarkers of diseases
}

\author{
Lucio Barile ${ }^{1}$ and Giuseppe Vassalli ${ }^{1,2 *}$ \\ ${ }^{1}$ Laboratory of Cellular and Molecular Cardiology, Fondazione Cardiocentro Ticino, Lugano, and Swiss \\ Institute for Regenerative Medicine (SIRM), Taverne, Switzerland \\ ${ }^{2}$ Dept. of Cardiology, University of Lausanne Medical Hospital (CHUV), Lausanne, Switzerland
}

* Addresses for correspondence:

Lucio Barile, Ph.D., SIRM, via ai Soi 24, 6807 Taverne, Switzerland (lucio.barile@cardiocentro.org)

Giuseppe Vassalli, M.D., Cardiocentro Ticino, via Tesserete 48, 6900 Lugano, Switzerland (giuseppe.vassalli@cardiocentro.org) 
Key words: exosome, microvesicle, drug delivery, miRNA

Abbreviations: AAV, adeno-associated virus; APC, antigen-presenting cell; CNS, central nervous system; CSF, cerebrospinal fluid; DC, dentritic cell; EBV, Ebstein-Barr virus; EGFR, epidermal growth factor receptor; EEF, eukaryotic elongation factors; ESCRT, endosomal-sorting complex required for transport; EV, extracellular vesicle; GFP, green fluorescent protein; GM-CSF, granulocyte/monocyte colony-stimulating factor; GPI, glycosylphosphatidylinositol; GP1, glypican-1; HCV, hepatitis C virus; HIV , human immunodeficiency virus; HSP, heat shock protein; HSPG, heparan sulfate proteoglycan; HSV, herpes simplex virus; ICAM, intercellular adhesion molecule; IL, interleukin; ILV, intraluminal vesicle; IFN- $\alpha$, interferon- $\alpha$; LAMP, lysosome-associated membrane protein; LFA-1, lymphocyte function-associated antigen-1; IncRNA, long noncoding RNA; MAGE, melanoma antigen gene; MHC, major histocompatibility complex; mRNA, messenger RNA; miRNA, microRNA; MRP-1, multidrug resistance-associated protein-1; MSC, mesenchymal stem cell; MVBs, multivesicular body; OVA, ovalbumin; PDGFR; platelet-derived growth factor receptor; PrPTSE, transmissible spongiform encephalopathy-associated prion protein; RVG, rabies viral glycoprotein; siRNA, small interfering RNA; tdTomato, tandem dimer Tomato; TGF $\beta$, transforming growth factor- $\beta$; TIM-4, T-cell immunoglobulin- and mucin-domain-containing molecule-4; TLR, Toll-like receptor; TNF, tumour necrosis factor; TSG101, tumour susceptibility gene 101; VEGF, vascular endothelial growth factor; VPS4, vacuolar protein sorting-associated protein 4; VSV-G, vesicular stomatitis virus-G 


\section{Abstract}

Virtually all cells in the organism secrete extracellular vesicles (EVs), a heterogeneous population of lipid bilayer membrane-enclosed vesicles that transport and deliver payloads of proteins and nucleic acids to recipient cells, thus playing central roles in cell-cell communications. Exosomes, nanosized EVs of endosomal origin, regulate many pathophysiological processes including immune responses and inflammation, tumour growth, and infection. Healthy subjects and patients with different diseases release exosomes with different RNA and protein contents into the circulation, which can be measured as biomarkers. The discovery of exosomes as natural carriers of functional small RNA and proteins has raised great interest in the drug delivery field, as it may be possible to harness these vesicles for therapeutic delivery of miRNA, siRNA, mRNA, IncRNA, peptides, and synthetic drugs. However, systemically delivered exosomes accumulate in liver, kidney, and spleen. Targeted exosomes can be obtained by displaying targeting molecules, such as peptides or antibody fragments recognizing target antigens, on the outer surface of exosomes. Display of glycosylphosphatidylinositol (GPI)-anchored nanobodies on EVs is a novel technique that enables EV display of a variety of proteins including antibodies, reporter proteins, and signaling molecules. However, naturally secreted exosomes show limited pharmaceutical acceptability. Engineered exosome mimetics that incorporate desirable components of natural exosomes into synthetic liposomes or nanoparticles, and are assembled using controllable procedures may be more acceptable pharmaceutically. In this communication, we review the current understanding of physiological and pathophysiological roles of exosomes, their potential applications as diagnostic markers, and current efforts to develop improved exosome-based drug delivery systems. 
Contents

1. Introduction

2. Vesicle classes

3. Biogenesis of exosomes

4. Lipid and protein composition of exosomes

5. RNA sorting into exosomes

6. Exosome uptake

7. Exosomes regulate cell functions

8. EVs as carriers of genetic information

9. EVs and pathogens

10. Exosomes as biomarkers of diseases

11. Therapeutic potential of naturally secreted EVs

12. Biodistribution of systemically delivered exosomes

13. Loading exosomes with exogenous cargo molecules

14. Targeted exosomes

15. Artificial exosome mimetics

16. Immune responses to exosomes

17. Experience in clinical trials

18. Conclusion

Acknowledgments

References

\section{Introduction}

First described as small vesicles by which maturating sheep reticulocytes discard obsolete cellular components (Johnstone et al. 1987; Pan \& Johnstone 1983; Trams et al. 1981), exosomes and other secreted extracellular vesicles (EVs) are now considered a prominent and universal form of cell-cell communication. Fundamentally all cells in the organism release EVs that are taken up by surrounding cells or circulate in the blood and eventually are taken up by cells at a distance. EVs transport biologically active 
molecules including proteins and nucleic acids that regulate gene expression and cellular function in target cells. As such, EVs mediate autocrine, paracrine, and endocrine effects that can be exploited therapeutically (Andaloussi et al. 2013). For example, mesenchymal stem cells (MSCs) and other progenitor cells used in cell therapy studies mediate cytoprotective, angiogenic, and regenerative effects that are recapitulated by the EVs they release (Baglio et al. 2012; Barile et al. 2014). This observation raises the exciting prospect of "cell therapy without the cells". Efforts to harness EVs as carriers of signaling molecules for therapeutic applications have been focused on exosomes, nanosized EVs of endosomal origin. Another area of intense investigation is the use of EVs as biomarkers of disease. Healthy subjects and patients with different diseases secrete EVs with different contents into the circulation and bodily fluids, which can be measured for diagnostic purposes.

To contextualise exosomes as potential biotherapeutics and drug delivery vectors within the broader field of vesicle biology, current knowledge of their biogenesis, composition, and functional roles in health and disease is summarized in the initial part of this communication. Potential roles of exosomes as indicators of diseases and novel exosome-based drug delivery systems will then be addressed. More comprehensive information on the classification, composition, and functions of EVs can be found at http://www.isev.org (International Society for Extracellular Vesicles), http://www.asemv.org (American Society for Exosomes and Microvesicles), http://microvesicles.org (Vesiclepedia, a compendium for EVs with continuous community annotation) (Kalra et al. 2012), http://www.exocarta.org (ExoCarta, a web-based compendium of exosomal cargo) (Keerthikumar et al. 2016), and http://exrna.org (Extracellular RNA communication program).

\section{Vesicle classes}

The classification of EVs as a heterogeneous mixture of membrane particles has been inconsistent and somewhat confusing. Three major populations have been distinguished: (i) exosomes, initially defined as 50-100-nm lipid bilayer particles released from cells; the size range was then increased to include particles as small as $20 \mathrm{~nm}$ in diameter and those as large as $150 \mathrm{~nm}$ in diameter, although a size range of 30-100 $\mathrm{nm}$ was used in most studies; (ii) microvesicles, also referred to as shedding vesicles (Shedden et al. 2003) or microparticles (Shantsila et al. 2010), which tend to be larger than exosomes (size range: 50-1,000 nm); (iii) apoptotic bodies (size range: 50-5,000 nm), which result from the fractionation of the cellular content of cells that die by apoptosis (Cline \& Radic 2004; Hristov et al. 2004). As apparent, these populations of EVs overlap in size. As a result of improved understanding of their biogenesis, the origin of EVs has become an important qualifier for their identity. Accordingly, exosomes are of EVs endosomal origin (Simons \& Raposo 
2009), whereas microvesicles typically form by membrane shedding, especially from injured or transformed cells (Muralidharan-Chari et al. 2010).

Based on comparative proteomics analyses, heterogeneous EV population can be subdivided into large, medium-sized, and small vesicles pelletting at low $(2,000 \times g)$, intermediate $(10,000 \times g)$, and high $(100,000$ $\times g$ ) sedimentation speed, respectively, the latter being the ultracentrifugation pellet classically considered as containing exosomes. Both exosomal and nonexosomal subpopulations were present within small vesicles (mean size $<200 \mathrm{~nm}$ ), which were further subdivided into four categories: (i) bona fide exosomes coenriched in exosome (CD63, CD81, CD9) and endosome markers such as syntenin-1 and tumour susceptibility gene 101 (TSG101); (ii) small EVs devoid of CD63/CD81 but enriched in CD9; (iii) small EVs devoid of CD63/CD9/CD81; (iv) small EVs enriched in extracellular matrix proteins or serum-derived factors (Kowal et al. 2016). For now, it is important to recognize that the nomenclature tends to be used rather loosely, and that it may be difficult in practice to distinguish exosomes from other EVs.

\section{Biogenesis of exosomes}

Endosomes arise from invaginations of the plasma membrane and fuse with molecular payloads sorted in the endoplasmic reticulum and processed in the Golgi complex, forming multivesicular endosomes (also referred to as multivesicular bodies; MVBs). When MVBs mature and eventually merge with the plasma membrane, their content is released into the extracellular space as exosomes (Figure 1). Rab GTPase proteins regulate fusion of MVBs with the cell membrane (Pfeffer 2010) and the spatio-temporal traffic of vesicles (Stenmark 2009). Endosomal-sorting complex required for transport (ESCRT) is the central molecular machinery of exosome formation at endosomes (Février \& Raposo 2004; Hurley 2010; Raiborg \& Stenmark 2009; Stoorvogel 2015). The ESCRT system comprises four multi-protein complexes (ESCRT-0, I, -II, -III), vacuolar protein sorting-associated protein 4 (VPS4)-Vta1, and the Alix homodimer. ESCRT-0 participates in cargo clustering and ubiquitination of endocytosed receptors (Katzmann et al. 2002; Katzmann et al. 2003). On endosomes, ubiquitinated membrane proteins enter the MVB pathway whereas nonubiquitinated proteins are recycled back to the plasma membrane or to the Golgi complex. TSG101, a component of ESCRT-I, forms complexes with ubiquinated cargo proteins and activates ESCRT-II. As a result, MVB proteins are sequestered and the de-ubiquitination enzyme is recruited to remove ubiquitin from the proteins prior to their sorting into intraluminal vesicles (ILVs). Molecules that inhibit ESCRT may hinder exosome release at once (Gross et al. 2012; Hoshino et al. 2013; Tamai et al. 2010). An RNA interference screen targeting 23 components of ESCRT and associated proteins showed that silencing of TSG101 
reduced the secretion of vesicle-associated CD63 and major histocompatibility complex class II (MHC-II) molecules, whereas depletion of VPS4B enhanced this secretion from MHC-II-expressing HeLa cells (Colombo et al. 2013). Silencing of Alix increased MHC-Il exosomal secretion. Formation of exosomes despite inhibition of ESCRT components points to the existence of an ESCRT-independent pathway possibly involving tetraspanins, heat shock proteins (HSPs), ceramides, cholesterol, and phosphophatidic acids (Kowal et al. 2014).

Not all vesicles in the MVBs are sorted for release. Together with autophagy, the MVB pathway delivers a significant share of cellular material to lysosomes. The autophagy (ATG)-core machinery and ESCRT couple cargo sorting to form transport intermediates (Huber \& Teis 2016). Why certain MVBs are sent to lysosomes for degradation (Denzer et al. 2000; Futter et al. 1996; Pant et al. 2012) versus fusion with plasma membrane for release is poorly understood. Secreted MVBs are richer in cholesterol (Möbius et al. 2002) and preferentially fuse with the plasma membrane (Verweij et al. 2012), as compared to degredatory MVBs.

\section{Lipid and protein composition of exosomes}

An in-depth discussion of the lipidomics and proteinomics of exosomes is beyond the scope of this article (for reviews, see Choi et al. 2013; Simpson et al. 2009). Briefly, exosomes released from different cell types contain different lipids and proteins. However, the lipid composition of exosomes differs from that of the plasma membrane of the parent cell, in part because exosomes also contain lipids from the Golgi. Exosome membranes are enriched in glycosphingolipids, cholesterol (Llorente et al. 2013; Morelli et al. 2004), phosphatidylserine (Laulagnier et al. 2004), and ceramide. Their lipid composition accounts for their unique rigidity. A role for ceramide in budding of exosome vesicles into MVBs was reported (Trajkovic et al. 2008). Exosomes are a heterogenous population of EVs expressing heterogenous patterns of surface molecules. Because they are frequently analysed as a bulk isolate, certain molecular markers are commonly found in exosomes. These markers include tetraspanins (CD9, CD63, CD81), Alix, HSP70, HSP90, GTPases (e.g., eukaryotic elongation factors [EEFs] $1 \mathrm{~A} 1$ and 2), and MHC molecules (Blanchard et al. 2002; Wolfers et al. 2001). However, some of the "common" markers may be restricted to subsets of exosomes derived from a single-cell source. CD9 participates in fusion processes in many cells (Miyado et al. 2000) and may facilitate fusion of exosomes to recipient cells (van den Boorn et al. 2011). Exosomes released from many, but not all, cells contain MHC class I (MHC-I) molecules. Human monocyte-derived dendritic cells (DCs) generated in vitro in the presence of IL-4 and IL-3 released exosomes with increased densities of MHC-I (Johansson et al. 2008). These exosomes and those secreted by various cell lines, unlike their parent cells, displayed a 
significant part of their MHC-I content in the form of fully folded disulfide-linked MHC-I dimers (Lynch et al. 2009). Formation of MHC-I dimers was controlled by the redox environment (Makhadiyeva et al. 2012). Moreover, different human tumour entities shed MHC-I-related chain molecules A and B (Chitadze et al. 2013). MHC-II molecules are expressed on exosomes released by antigen-presenting cells (APCs) including DCs, macrophages, B cells, microglia, and intestinal epithelial cells. Immature DCs express low levels of MHC-II. In these cells, peptide-loaded MHC-II molecules are ubiquitinated, resulting in their endocytosis and sorting into ILVs for lysosomal degradation. Conversely, in activated DCs MHC-II molecules are not ubiquitinated and are expressed on the cell surface. Sorting of MHC-II into exosomes may be independent of ubiquitination. In DCs loaded with antigen, cognately interacting antigen-specific CD4+ T cells activated an alternate MVB sorting mechanism for MHC-II whereby DCs formed MVBs with MHC-II and CD9 carrying luminal vesicles that were secreted as exosomes and transferred to the interacting $T$ cells (Buschow et al. 2009). Another study showed that soluble MHC-II proteins promoted suppressive activity in CD4+ T cells and that exosome-mediated immune tolerance was dependent upon MHC-II (Bakela et al. 2015). Moreover, exosomes from DCs and other APCs mediated intercellular transfer of MHC-1/II leading to the formation of so-called "MHC-dressed cells" that activated or regulated T cells via pre-formed antigen peptide-MHC complexes without requiring any further processing (Nakayama 2015).

While exosomes carry proteins expressed by the parent cell, their protein composition is not identical with that of the parent cell, indicating selective protein sorting. The underlying mechanism is poorly understood but may involve interactions between tetraspanins and other transmembrane proteins that form protein complexes in membrane microdomains (Yanez-Mo et al. 2009). For example, the multivalent adaptor syntenin couples to membrane proteins and to Alix which, in turn, binds to ESCRT-III and participates in the sorting of syndecan membrane proteins into exosomes (Baietti et al. 2012; Roucourt et al. 2015).

\section{RNA sorting into exosomes}

Exosomes contain nucleic acids including mRNA, microRNA (miRNA), ribosomal RNA, long noncoding RNA (IncRNA), and variably some DNA. miRNA is a class of small noncoding RNAs that regulate gene expression at the post-transcriptional level (Yates et al. 2013). The miRNA repertoire of exosomes varies as a function of the parent cell and its physiological state (Gibbings et al. 2009). The composition of exosomes is a tightly regulated process that is modulated by environmental factors including cell activation and stress conditions (De Jong et al. 2012). The complexity of the mechanisms underlying miRNA sorting into exosomes is only beginning to emerge (Villarroya-Beltri et al. 2014). Knockdown of the ESCRT proteins did not affect this 
process (Kosaka et al. 2010). Recent evidence suggests that specific motifs present in certain miRNAs may facilitate their incorporation into exosomes through binding to specific chaperon proteins, such as sumoylated hnRNPA2B1, a heterogeneous nuclear riboprotein that directs miRNA trafficking to MVBs and its release through exosomes (Villarroya-Beltri et al. 2013). In macrophages, cell activation-dependent changes of miRNA target levels appeared to regulate miRNA sorting into exosomes (Squadrito et al. 2014). In human B cells, the distribution of miRNAs subsets between the cells and their secreted exosomes was found to be nonrandom, as 3' end-adenylated miRNAs were overrepresented in cells and 3' end-uridylated miRNAs were overrepresented in exosomes (Koppers-Lalic et al. 2014). These findings suggest that miRNA sorting into exosomes may be regulated by post-transcriptional modifications. Understanding how proteins and RNA are sorted into exosomes will be crucial to appreciate how cells modify their molecular payloads under different conditions.

\section{Exosome uptake}

Exosomes interact with target cells through multiple mechanisms (de Curtis \& Meldolesi 2012; Mittelbrunn \& Sánchez-Madrid 2010). Receptor binding can initiate exosome uptake (Miyanishi et al. 2007; Nolte-'t Hoen et al. 2009). Fusion (Prada \& Meldolesi 2016) and endocytotic processes including clathrin-coated pits, pinocytosis, caveolae, macropinocytosis (Fitzner et al. 2011), and phagocytosis may participate in the internalization of exosomes by different cell types (Morelli et al. 2004; Tian et al. 2010). Inhibition of exosomal uptake using dynasore, a potent endocytosis inhibitor, did not completely block the uptake of exosomes secreted by Ebstein Barr virus (EBV)-infected cells (Petgel et al. 2010), consistent with multiple entry mechanisms for exosomes including through the plasma membrane. Binding of exosomes to the plasma membrane is mediated by the classical adhesion molecules involved in cell-cell interactions, e.g., integrins and intercellular adhesion molecules (ICAMs). Additional exosomal molecules that participate in cellular uptake include lactadherin, phosphatidylserine, heparan sulfate proteoglycans (HSPGs), and tetraspanins. Tetraspanin-dependent regulation of exosome uptake by endothelial cells was reported (Rana \& Zoller 2011). Receptors contributing to uptake include integrins, scavenger receptors, complement receptors, and T-cell immunoglobulin- and mucin-domain-containing molecule-4 (TIM-4) that binds to phosphatidylserine (György et al. 2015; Record et al. 2011). Ligand-receptor signaling through surface ligands is involved in many processes including T-cell activation by DC-derived exosomes (Thery et al. 2002), angiogenesis (Martinez \& Andriantsitohaina 2011), and cancer progression (Cho et al. 2011). Microvesicles from glioma cells expressing the truncated form of epidermal growth factor receptor (EGFR), 
EGFRvIll, were shown to transfer this oncogenic protein to surrounding tumour cells that did not express it (Al-Nedawi et al. 2009). This observation exemplified EV-mediated transfer of surface receptors to acceptor cells through fusion with their plasma membrane.

EVs can exploit viral entry routes for cargo delivery (van Dongen et al. 2016). Both viral and nonviral molecules may facilitate fusion of EVs with acceptor cells. Exosomes from hepatitis $\mathrm{C}$ virus (HCV)-infected cells were enriched in CD81 and HCV glycoproteins and were possibly taken up through fusion (Masciopinto et al. 2004). Both human immunodeficiency virus (HIV) and EVs rely on lectins, sialic acid binding molecules expressed on a variety of leukocytes and stromal cells, as target cell receptors. HIV was shown to target myeloid DCs via the receptor CD169/Siglec-1, a lectin binding to the ganglioside-3 present on the surface of virus particles (Puryear et al. 2012). CD169 also captured B-cell-secreted exosomes by macrophages (Saunderson et al 2014). HSPGs appeared to participate in the capture of herpes simplex virus (HSV) and in the internalisation of exosome-like EVs produced by cancer cells (Christianson et al. 2013).

The mechanism through which exosome cargo is released into the cytoplasm and the fate of exosomal components in acceptor cells are incompletely understood. Real-time analysis using fluorescence microscopy and single particle tracking showed that exosomes from PC12 cells were attached onto plasma membrane from the medium and moved in a slow drifted mode indicative of diffusion in local microenvironments of cytoplasm (Tian et al. 2013). The motion of exosomes then changed to a rapid directed mode, suggesting exosome internalization and active transport along actin filaments or microtubules to lysosomes. Recent evidence suggests that exosomes may be recruited as single vesicles to the cell body by surfing on filopodia as well as filopodia grabbing and pulling motions to reach endocytic hot spots at the filopodial base. After internalization, exosomes shuttle within endocytic vesicles to scan the endoplasmic reticulum before being sorted into lysosomes (Heusermann et al. 2016).

\section{Exosomes regulate cell functions}

A variety of cell types including DCs and other APCs (Thery et al. 2002), mast cells (Skokos et al. 2002), B and T cells (Clayton et al. 2005; Taylor \& Gercel-Taylor 2005), intestinal epithelial cells (van Niel et al. 2001), neurons (Faure et al. 2006), cardiac myocytes (Gupta \& Knowlton 2007), MSCs (Lai et al. 2010), endothelial cells (de Jong et al. 2012), and cancer cells (Taylor \& Gercel-Taylor 2005; Zhao et al. 2015) secrete EVs. Early studies investigated exosomes from immune cells. Mature DCs secrete exosomes containing MHC-I/II presenting antigens to the immune system (Segura et al. 2005). DC-derived exosomes were shown to facilitate immune cell-dependent tumour rejection (Zitvogel et al. 1998). Donor DC-derived exosomes 
promoted alloimmune responses and solid organ allograft rejection (Liu et al. 2016). On the other hand, exosomes from IL-10-treated DCs suppressed inflammation and collagen-induced arthritis in mice (Kim et al. 2005). The T-cell receptor is located on the surface of microvesicles budding at the immunological synapse center. B cells bearing cognate MHC proteins receive T-cell receptors from $\mathrm{T}$ cells and initiate intracellular signals in response to isolated synaptic microvesicles (Choudhuri et al. 2014). Activated T cells released miRNA-loaded exosomes that regulated immunity by targeting APCs (Mittelbrunn et al. 2011). However, secretion of EVs with T-cell costimulatory activity by cytotoxic CD4+ T cells was reported (van der Vlist et al. 2012). Placenta-derived EVs may suppress maternal immune rejection of the fetus by inhibiting Tcell signaling and by promoting apoptosis of activated lymphocytes through display of Fas ligand and tumour necrosis factor (TNF)-related apoptosis-inducing ligand (Stenqvist et al. 2013; Taylor et al. 2006). During viral infection, placental exosomes transferred viral resistance to non-placental cells via delivery of autophagy-inducing miRNAs (Delorme-Axford et al. 2013). In a different context, regulatory T cells secreted miRNA-loaded exosomes that inhibited pathogenic T helper (Th)-1 cells (Okoye et al. 2014). Exosomemediated, MHC-II-dependent immune tolerance (Bakela et al. 2015) has been mentioned above. A recent study showed that exosomal miR-146a and miR-155 passed between immune cells in vivo, and that exosomal miR-146a inhibited endotoxin-induced inflammation in mice whereas miR-155 worsened it (Alexander et al. 2015). Regulatory roles of EVs in inflammation in various inflammatory diseases (Buzas et al. 2014), arteriosclerosis (Hulsmans \& Holvoet 2013), and in the central nervous system (CNS) (Gupta \& Pulliam 2014) have been reported.

In the CNS, EVs are prominently involved in shuttling reciprocal signals between myelinating glia and neurons, thus promoting neuronal survival, immune responses mediated by microglia, and synapse assembly and plasticity while also playing important roles in the spread of neurodegenerative disorders and brain cancer (Budnik et al. 2016; Rajendran et al. 2014). Oligodendroglia-derived exosomes enhanced the viability of cultured neurons under stress conditions and were detected in neurons after in vivo injection into the mouse brain (Fruhbeis et al. 2012). Circulating exosomes from patients with Parkinson disease protected neurons against stress (Tomlinson et al. 2015). On the other hand, EVs participate in the packaging and spread of misfolded proteins associated with neurodegenerative diseases (Coleman \& Hill 2015). Exosomemediated transmission of aggregates of dysbindin-1B isoform encoded by the schizophrenia susceptibility gene DTNBP1 induced toxic effects in neurons a long distance away from the initial aggregation site in the mouse brain (Zhu et al. 2015). In patients with Alzheimer disease, beta-amyloid peptide released from the cells in association with exosomes accumulated in the plaques in the brain (Rajendran et al. 2006). The 
exosome secretory pathway transported amyloid precursor protein carboxyl-terminal fragments from the cell into the brain extracellular space (Perez-Gonzalez et al. 2012). Transmissible spongiform encephalopathyassociated prion protein (PrPTSE) was detected in plasma EVs in a mouse-adapted variant of CreutzfeldtJakob disease (Saa et al. 2014). The neutral sphingomyelinase pathway was shown to regulate packaging of the prion protein into exosomes (Guo et al. 2015).

EVs play central roles in tumour growth and metastasis. Tumour antigen presented by tumour-derived EVs in association with MHC was taken up and processed by DCs, which then triggered potent CD8+ T-cellmediated anti-tumour immune responses (Blanchard et al. 2002; Wolfers et al. 2001). Distinct subsets of tumour-derived EVs modulate anti-tumour immune responses, thus facilitating tumour growth (Taylor \& Gercel-Taylor 2005; Zhao et al. 2015) via regulation of gene expression (Qu et al. 2009; Valadi et al. 2007), cell proliferation (Qu et al. 2009), migration and invasion (Graves et al. 2004; Higginbotham et al. 2011; Sung $\mathrm{BH}$ et al. 2015). Glioma cells were shown to deliver EGFRvIll via EVs to surrounding glioma cells, in which EGFRvIII activated transforming signaling pathways and regulated the expression of target genes including vascular endothelial growth factor (VEGF), anti-apoptotic Bcl-x(L), and cyclin-dependent kinase inhibitor p27 (Al-Nedawi et al. 2008). Tumour-derived exosomes we shown to deliver proangiogenic peptides and miRNAs to microvascular endothelial cells to promote tumour angiogenesis (Hood et al. 2009; JanowskaWieczorek et al. 2005; Skog et al. 2008; Zhang et al. 2014). Exosomes from pancreatic cancer cells initiated pre-metastatic niche formation in the liver (Costa-Silva et al. 2015). Exosomes from highly metastatic melanomas induced vascular leakiness at pre-metastatic sites and "instructed" bone marrow progenitor cells toward a proangiogenic phenotype (Peinado et al. 2012). The miRNA content of cancer-derived EVs regulates tumour growth and migration. For instance, miR-105 secreted by metastatic breast cancer cells facilitated cell migration by targeting the tight junction protein ZO-1 (Zhou et al. 2014). Recent evidence suggests that exosomes may participate in the transfer of drug resistance in cancer. Exosome-mediated transfer of functional P-glycoprotein and multidrug resistance-associated protein-1 (MRP-1) from drug resistant to drug sensitive tumour cells and acquisition of multi-drug resistance by the latter was reported (Ji et al. 2015; Lopes-Rodrigues et al. 2016). Another recent study showed that MSC-derived exosomes were taken up and down-regulated transcriptional regulatory genes in cancer cells (Yang et al. 2015). These findings illustrate EV-mediated bi-directional cross-talk between tumour and non-tumour cells.

\section{EVs as carriers of genetic information}


By delivering nucleic acids to target cells, EVs exchange genetic information between cells. Exosomes from a mouse and a human mast cell line (MC/9 and HMC-1, respectively) and from primary bone marrow-derived mouse mast cells were shown to contain RNA from $\sim 1,300$ genes (Valadi et al. 2007). In vitro translation showed that exosomal mRNAs were functional. After transfer of mouse exosomal RNA to human mast cells, new mouse proteins were found in the recipient cells, indicating that transferred exosomal mRNA was translated after entering the cell. Additional reports supported EV-mediated functional delivery of mRNA (Deregibus et al. 2007; Mizrak et al. 2013; Skog et al. 2008) and small RNAs (Choudhuri et al. 2014; Mittelbrunn et al. 2011; Skog et al. 2008; Zhou et al. 2014) to acceptor cells. EVs derived from either the lung or liver entered bone marrow cells in vitro and induced expression of proteins specific for the originating lung or liver tissue (Quesenberry et al. 2014). These findings indicate that EVs have the capacity to change the phenotype of neighbouring cells.

Circulating viral and tumour-derived miRNAs are packaged into EVs (Chugh et al 2013) that protect RNA from ribonuclease degradation (Castanotto \& Rossi 2009). Conversely, synthetic naked miRNA has a short half-life in the circulation, which can be improved by chemical modifications (Wang et al. 2015), and to a greater extent by loading into EVs. miRNA delivered via exosomes repressed target genes in recipient cells (Montecalvo et al. 2012; Pegtel et al. 2010; Squadrito et al. 2014).

To what extent EV-delivered RNA is intact and functional is unclear. A recent study showed that while both exosomes and microvesicles from transiently transfected cells delivered reporter mRNA to recipient cells, the delivered mRNA was rapidly degraded and was not translated (Kanada et al. 2015). Microvesicles, but not exosomes, delivered functional plasmid DNA in vivo. Another study addressed exchanges of tumour-derived EVs between cell populations and cargo RNA translation (Lai et al. 2015). EV membranes were labeled with enhanced green fluorescent protein (EGFP) and tandem dimer Tomato (tdTomato) N-terminally fused with a palmitoylation signal (PalmEGFP, PalmtdTomato). To monitor EV-RNA cargo, transcripts encoding PalmtdTomato were tagged with MS2 RNA binding sequences and detected by co-expression of a bacteriophage MS2 coat protein-EGFP fusion. Multiplexing of fluorescent and bioluminescent EV membrane reporters demonstrated rapid dynamics of EV uptake and translation of EV-delivered cargo mRNAs in cancer cells within $1 \mathrm{hr}$ after horizontal transfer between cells. A distinct study addressed the abundance of miRNA molecules in exosome preparations from five different sources (plasma, seminal fluid, DCs, mast cells, and ovarian cancer cells). Exosome fractions contained only a small minority of the miRNA content of plasma, and the abundance of individual miRNAs in exosomes was low (Chevillet et al. 2014). Functional roles of exosomal miRNA transfer were studied in a model of macrophage-to-endothelial cell communication 
(Squadrito et al. 2014). Endothelial cells deficient in Dicer, a RNase III enzyme required for the generation of miRNAs, were cultured in the presence of exosomes from Dicer-proficient or Dicer-deficient macrophages. Although bona fide transfer of miRNA activity from macrophages to endothelial cells via exosomes was observed, the contribution of exogenous miRNAs to target gene repression was modest. Most of the exosomes taken up by endothelial cells ended up in lysosomes. Differences in the donor cell, experimental model, and purification procedure may account for the conflicting results from these studies.

\section{EVs and pathogens}

EVs share biological features with enveloped viruses, such as HSV-1, EBV, and vaccinia virus regarding biogenesis, biophysical properties, cell entry, and functional protein and RNA delivery to target cells (Meckes \& Raab-Traub 2011). Several enveloped viruses exploit the cellular vesiculation machinery for budding and assembly (Rossman \& Lamb 2011). EVs secreted by cells infected by enveloped viruses carry viral envelope factors that mediate EV attachment and possibly fusion with target cells. This process is so efficient that EVs outcompete actual viral particles for cell entry (Vallhov et al. 2011). Exosomes released from HSV-1- or EBV-infected cells exported functional viral mRNA and miRNA to uninfected cells (McLauchlan et al. 1992; Meckes et al. 2010; Pegtel et al. 2010). Microvesicles from HIV-infected cells transferred CD4 receptor and chemokine receptor CCR5 to noninfectable cells, which acquired susceptibility to infection (Ratajczak et al. 2006). HIV-1-mediated activation of the DC immunoreceptor triggered the release of exosomes containing the pro-apoptotic protein DAP-3 that induced apoptosis in uninfected CD4 ${ }^{+}$T cells (Mfunyi et al. 2015). A possible role for EVs in the transmission of PrPTSE has been mentioned above (Saa et al. 2014). A role for EVs in bacterial infection is exemplified by recent data showing lysosome exocytosis and expulsion of exosome-encased uropathogenic E. coli infecting bladder epithelial cells (Miao et al. 2015).

\section{Exosomes as biomarkers of diseases}

Exosomes released by cells into the circulation and bodily fluids display different protein and RNA contents in healthy subjects and patients with different diseases, which can be measured as potential diagnostic markers (Clayton et al. 2003; Pant et al. 2012; Revenfeld et al. 2014). Tumour-derived exosomes are rich in miRNAs that may serve as tumour markers (Kumar et al. 2015; Mishra 2014; Schwarzenbach 2015). Patients with glioblastoma multiforme differed from healthy subjects in their RNA content of serum EVs (Noerholm et al. 2012; Taylor \& Gercel-Taylor 2008). Circulating exosomes from glioblastoma patients showed increased levels of EGFRvIII mRNA, which can be measured for glioblastoma diagnosis (Skog et al. 
2008). This method may serve the role of a "fluid-biopsy", thus avoiding the need for a surgical procedure to remove tissue biopsies from the brain for detection of EGFRvIll protein. EGFR localized to exosome membranes was tested as a possible marker for lung cancer diagnosis (Yamashita et al. 2013).

Proteoglycan glypican-1 (GP1)-positive exosomes were detected in the serum of patients with pancreatic cancer with absolute specificity and sensitivity, distinguishing them from healthy subjects and patients with a benign pancreatic disease (Melo et al. 2015). Levels of GP1-positive exosomes correlated with tumour burden and survival of pre- and post-surgical patients, suggesting a prognostic relevance of the marker. In mice, GP1-positive exosomes reliably detected pancreatic intraepithelial lesions despite negative signals by magnetic resonance imaging. Plasma microvesicles secreted by prostate acinar cells were investigated as a starting material for the identification of novel markers for prostate cancer (Tavoosidana et al. 2011). Proteomics profiling of exosomes identified candidate markers of the disease (Duijvesz et al. 2013). Patients who experienced recurrence of hepatocellular carcinoma after liver transplantation showed increased levels of a miRNA biomarker in serum exosomes (Sugimachi et al. 2015).

Exosomes have also been evaluated as biological indicators for a number of non-cancer diseases of multiple organs including the CNS (Kawikova \& Askenase 2015), liver (Masyuk et al. 2013), kidney (Spanu et al. 2014), lung (Levanen et al. 2013), and arteries (Hoefer et al. 2015). In the CNS, tau-induced neurodegeneration results from extracellular accumulation of abnormally processed tau protein (Saman et al. 2012). In the M1C neuroblastoma tauopathy model, Tau appeared to be exported via exosomes and was enriched in AT270 phospho-tau, a biomarker for early Alzheimer disease. The elevated cerebrospinal fluid (CSF) levels of AT270 phospho-tau seen in mild to moderate cases of sporadic Alzheimer disease resulted from selective enrichment of phospho-tau in exosomal fractions of CSF relative to total CSF tau. The increase in phospho-tau with disease onset was associated with a marked spike in the exosomal fraction. In another study, levels of autolysosomal proteins (cathepsin D, lysosome-associated membrane protein [LAMP] 1, and ubiquitinylated proteins) in neurally derived serum exosomes distinguished patients with preclinical Alzheimer disease from controls and patients with fronto-temporal dementia (Goetzl et al. 2015). Proteomics profiling identified differentially abundant proteins in serum exosomes from patients with Parkinson disease and healthy subjects (Tomlinson et al. 2015). With respect to lung disease, exosomes from broncho-alveolar lavage fluids from asthmatic patients or healthy subjects exhibited different miRNA profiles (Levanen et al. 2013). Regarding cardiovascular disease, increased miR-192 levels in serum exosomes predicted the subsequent development of heart failure in patients after acute myocardial infarction (Matsumoto et al. 2013). Finally, urinary exosomes haveen be used as starting material for biomarkers for 
renal, urogenital, and systemic diseases (Huebner et al. 2015; Spanu et al. 2014). Increased levels of fetuinA in urinary exosomes correlated with acute renal injury (Zhou et al. 2006). Ongoing clinical studies of diagnostic EV markers are summarized in Table 1. Most studies are focused on cancer, and one study addresses Parkinson disease.

Despite numerous reports of significant associations of EV biomarkers with various diseases, the results of individual studies match poorly. Methodological differences in EV purification may contribute to this mismatch (Taylor \& Shah 2015). For a given application, it is mandatory to check the sensitivity and specificity of the test under well-defined conditions.

\section{Therapeutic potential of naturally secreted EVs}

EVs naturally released from certain cell types exhibit therapeutic potential. MSC-derived EVs recapitulate immunomodulatory and cytoprotective activities of their parent cells (Baglio et al. 2012; Yeo et al. 2013). Bone marrow MSC-derived exosomes were protective in models of myocardial ischemia/reperfusion injury (Lai et al. 2010), hypoxia-induced pulmonary hypertension (Lee et al. 2012), and brain injury (Doeppner et al. 2015; Zhang et al. 2015). These exosomes likewise stimulated neurite outgrowth in cultured astrocytes via miR-133b transfer (Xin et al. 2012). Human umbilical cord MSC-derived EVs were protective in models of acute renal injury (Bruno et al. 2009) and liver fibrosis (Li et al. 2013b). MSC-derived exosomes inhibited breast cancer growth via VEGF down-regulation and miR-16 transfer in mice (Lee et al. 2013). However, altered functionalities of cancer cell lines (Yang et al. 2015), attenuated immune rejection of tumour (Kordelas et al. 2014), and increased tumour growth as a result of MSC-derived exosomes were likewise reported. Also, islet MSC-derived exosomes induced autoimmunity in NOD mice (Rahman et al. 2014).

EVs secreted by immune cells induce immune stimulation or inhibition under different conditions. The ability of DC-derived EVs to present antigens to the immune system has been exploited in EV-based vaccination against cancer and infection (Viaud et al. 2010). A potential advantage of these vaccines is that they preferentially induce Th1-type responses and cell-mediated immunity, which is key to fight against viral and bacterial infections. EVs released by DCs pulsed with diphtheria toxoid induced Th1-type responses in naïve recipients (Colino \& Snapper 2006). Exosomes carrying mycobacterial antigens induced a Th1-type reaction against M. tuberculosis (Cheng \& Schorey 2013). Conversely, protein subunit-based vaccines induced preferentially Th2-type responses and antibody-mediated immunity. Exosomes carrying mycobacterial antigens outperformed protein subunit-based vaccines for growth inhibition of $M$. tuberculosis in the mouse lung (Cheng \& Schorey 2013). 
Regulatory DCs overexpressing immunomodulatory cytokines (IL-4, IL-10, transforming growth factor- $\beta$ [TGFB]) secreted EVs with immunosuppressive activity in models of collagen-induced arthritis and druginduced colitis (Bianco et al. 2007; Robbins \& Morelli 2014). In a heart transplant model, exosomes from immature donor DCs increased splenic Foxp3 ${ }^{+}$regulatory T cells and delayed graft rejection (Pêche et al. 2004). Exosomes secreted by activated T cells induced death of the parent cells via expression of Fas ligand (Monleon et al. 2001). Exosomes released from interferon- $\alpha$ (IFN- $\alpha$ )-treated macrophages or liver sinusoidal cells delivered antiviral RNAs and proteins to hepatocytes and reduced replication of hepatitis B virus in a hepatitis B model (Li et al. 2013a).

We recently reported that human adult cardiac-resident progenitor cells secreted EVs with cardioprotective and proangiogenic activities. Intramyocardial injection of these EVs reduced scar and improved cardiac function after myocardial infarction in rats (Barile et al. 2014). Exosomes purified from human peripheral blood activated the HSP70/Toll-like receptor (TLR) 4 pro-survival pathway in cardiac myocytes (Vicencio et al. 2015). EVs released from endothelial progenitor cells stimulated angiogenesis in cultured endothelial cells via miR-126 and miR-296 transfer (Deregibus et al. 2007), promoted angiogenesis in a hind-limb ischemia model (Ranghino et al. 2012), and protected from renal ischemia/reperfusion injury (Cantaluppi et al. 2012). Exosomes secreted by differentiating neuronal cells stimulated neuronal differentiation in human MSCs (Takeda \& Xu 2015). Exosomes from embryonic CSF supported amplification of cultured neural stem cells (Feliciano et al. 2014). Serum exosomes containing miR-219 stimulated CNS myelination (Pusic \& Kraig 2014). Neuronal exosomes sequestered intracerebral amyloid- $\beta$ peptide (Yuyama et al. 2015). Infusion of neuronal exosomes into brains decreased $A \beta$ and amyloid depositions in a mouse model of Alzheimer disease. These findings highlight the role of neuronal exosomes in $A \beta$ clearance, suggesting that their downregulation might relate to $A \beta$ accumulation and, ultimately, the development of the disease.

\section{Biodistribution of systemically delivered exosomes}

After systemic administration, the biodistribution of EVs influences the therapeutic efficacy and toxicity (György et al. 2015). Like any other nanotherapeutics, unmodified exosomes delivered systemically in animals accumulated preferentially in liver, kidney, and spleen, and were rapidly eliminated by bile excretion, renal filtration, or phagocytosis in the reticuloendothelial system, respectively. Exogenous exosome concentrations in target tissues were very low. The fate of delivered EVs in vivo was assessed using luciferase and metabolic biotinylation labeling, followed by bioluminescence and fluorescence-mediated tomography imaging in mice (Lai et al. 2014). EVs were detected predominantly in the spleen, liver, lung, 
and kidney $30 \mathrm{~min}$ after i.v. injection. A rapid distribution phase of $20 \mathrm{~min}$, likely reflecting fast redistribution of EVs to the liver and lung, was followed by a longer distribution phase reflecting elimination from the body through the liver and kidney. Other studies investigated the fate of i.v. injected melanoma-derived exosomes labeled with PKH67 or XenoLight DiR membrane dyes. PKH67-labeled exosomes were detected in the liver, spleen, lung, and bone marrow (Peinado et al. 2012). XenoLight DiR-labeled exosomes were found in the liver, lung, spleen, kidney, brain, intestines, and tumour tissue (Ohno et al. 2013a; Ohno et al. 2013b). However, a significant and prolonged association of exosomes injected intra-tumourally with tumour tissue was reported (Smyth et al. 2015).

Exosomes traverse complex biological barriers such as the intestinal lining and the blood-brain barrier. An intranasal route of administration was applied to exosomal delivery to the brain. Intranasally administered EVs loaded with curcumin, and anti-oxidant agent, crossed the blood-brain barrier, localized in microglial cells in the brain, and inhibited autoimmune encephalomyelitis in mice (Zhuang et al. 2011). Intranasally delivered exosomes loaded with catalase, an anti-oxidant enzyme, were taken up by microglial cells in the brain and mediated neuroprotective effects in mouse models of Parkinson disease (Haney et al. 2015).

\section{Loading exosomes with exogenous cargo molecules}

As natural carriers of signaling molecules, exosomes offer appealing features for therapeutic delivery, including biocompatibility, stability in the circulation, biological barrier permeability, low immunogenicity, and low toxicity. Expression of CD55 and CD59 may contribute to EV stability in the blood by preventing complement-mediated lysis (Clayton et al. 2003). Being nano-sized, exosomes may evade fast clearance by the mononuclear phagocyte system (van den Boorn et al. 2011).

EVs can be loaded with therapeutic cargo molecules. Loading strategies with exogenous molecules can be subdivided into two major groups: ex vivo extracellular EV loading, and in vitro intracellular EV loading during EV biogenesis (György et al. 2015). Passive loading techniques have been employed to load EVs with miRNA (Ohno et al. 2013a; Ohno et al. 2013b), small hairpin RNA (Rechavi et al. 2009), mRNA (Deregibus et al. 2007; Mizrak et al. 2013; Skog et al. 2008), and proteins (Bianco et al. 2007; Robbins \& Morelli 2014). However, ex vivo loading of purified EVs with small RNA molecules may impair the functionalities of these molecules (Vader et al. 2014). EVs share several physico-chemical properties with liposomes. Liposomal nucleic acid transfer involves electrostatic complexation of the negatively charged nucleic acids via cationic lipids, which may cause toxicity. The negative surface charge of EVs prevents electrostatic nucleic acid complexation. To circumvent this hurdle, small interfering RNA (siRNA) was pre-complexed via cationic 
liposomes prior to fusion with EVs (Wahlgren et al. 2012). In another study, exosome-like nanovesicles from tolerized suppressor $T$ cells from miR-150-deficient mice were incubated with miR-150, and the nanovesicles acquired the immunosuppressive properties observed with nanovesicles from wild-type mice (Bryniarski et al. 2013). This study did not address the precise location of the exogenous miRNA with respect to the vesicles; however, this miRNA was likely located to the outer surface of the vesicles. Encapsulation of the nucleic acids in the core of the vesicles, mimicking their natural location, may be preferable.

Exosomes can be loaded with therapeutic miRNA mimic or antagonist using several techniques (Xitong \& Xiaorong 2016): (i) Cotransfection of producer cells with two plasmids, or cotransduction with two viruses, one encoding the precursor miRNA, hsa-miRNA, and the other encoding the fusion targeting peptide, or alternatively one bicistronic vector containing the two expression cassettes; (ii) Electroporation can be used to create transient pores in the membrane to facilitate the migration of small RNA through it. This technique achieved efficient loading of exosomes with miRNAs and knockdown of their target gene expression (Alvarez-Erviti et al. 2011; Cooper et al. 2014; Tian et al. 2014); (iii) transient transfection of miRNAs using commercial available transfection reagents.

siRNA is a class of double-stranded RNAs that interfere with the expression of specific genes with complementary nucleotide sequences by causing mRNA breakdown. The excellent sequence specificity of siRNAs reduces the risk for off-target effects. In contrast, miRNAs do not require full binding to their target mRNA sequences and act synergistically on multiple target genes. Up to $25 \%$ siRNA loading efficiency was achieved by electroporating DC-derived exosome/siRNA mixtures (Alvarez-Erviti et al. 2011). Exosomes loaded with siRNA against BACE1, a protein involved in the pathogenesis of Alzheimer disease, knocked down mRNA of BACE1 by $60 \%$ and BACE1 protein by $62 \%$, and reduced the harmful $\beta$-amyloid $1-42$ protein by $55 \%$ in the brain cortex of mice. In a rat model of spinal cord injury, embryonic cortical neuron-derived exosomes loaded with siRNA against apoptosis speck-like protein containing a caspase recruitment domain, an inflammatory factor that is upregulated after spinal cord injury, knocked down target protein levels by $76 \%$ (de Rivero Vaccari et al. 2015). While up to $90 \%$ siRNA loading efficiency was reported in monocyte-derived EVs (Wahlgren et al. 2012), duplication of the experiments by an independent group suggested that siRNA encapsulation might be largely due to unspecific aggregate formation resulting from the interaction of multivalent cations, released from the metal electrodes in the electroporation cuvette, independent of the presence of EVs (Kooijmans et al. 2013). These findings illustrate the variable efficiency of EV loading with siRNA by electroporation, and the therapeutic potential of exosomal siRNA transfer. 
Electroporation can also be used to load EVs with small-molecule drugs. Up to $20 \%$ encapsulation efficiency was achieved by electroporating DC-derived exosomes/doxorubicin mixtures (Tian et al. 2014). Alternatively, synthetic drugs can be bound non-specifically to EVs. Mixing curcumin with exosomes improved the bioavailability and anti-inflammatory efficacy of this drug in a model of LPS-induced septic shock (Sun et al. 2010). Incubation of monocyte/macrophage-derived exosomes with catalase at room temperature and permeabilization with soponin, freeze-thaw cycles, sonication, and extrusion resulted in high loading efficiency, sustained delivery, protection of catalase from protease degradation, and exosome-mediated neuroprotection in models of Parkinson disease (Haney et al. 2015).

A frequently applied in vitro intracellular strategy of EV loading with cargo molecules uses engineered EVproducing cells, as discussed below. An alternate approach relies on the trafficking of oligomeric membraneanchored proteins to EVs. The exogenous protein is fused with two domains that mediate aggregation and membrane localisation, e.g., by adding a myristoyl moiety. This approach was validated using a GFP reporter protein (Shen et al. 2011). Interference of protein oligomer formation with protein function in target cells remains of potential concern (Marcus \& Leonard 2013).

Another strategy for loading EVs with nucleic acids exploits viral packaging mechanisms. During the production of adeno-associated virus (AAV) vectors, a fraction of the vectors was associated with exosomes and outperformed conventionally purified AAV vectors in transduction efficiency (Maguire et al. 2012). Also, hepatitis $A$ virus released by cells was cloaked in host-derived membranes that resembled exosomes and was fully infectious (Feng et al. 2013). Thus, nonenveloped viruses can associate with EVs to form virus-EV hybrid particles that combine the respective advantages of EVs (low immunogenicity, targeting) and viruses (stable gene expression).

Regardless of the loading method used, unintended incorporation of undesired cell-derived proteins or RNA (e.g., retroviral genomes) (Gould et al. 2003) into EV may occur. Novel technologies that eliminate undesired molecules from EV-producing cells or prevent their incorporation into the released vesicles are needed.

\section{Targeted exosomes}

The biodistribution profiles of naturally secreted EVs with no modifications to their composition prohibit their systemic administration. However, EVs secreted by a few cell types exhibit target selection. DC-derived EVs are recruited by activated $\mathrm{T}$ cells through interactions between ICAM-1 expressed on DC-EVs and lymphocyte function-associated antigen-1 (LFA-1) expressed on T cells (Nolte-'t Hoen et al. 2009). B-cellderived exosomes are recruited by hepatic and splenic macrophages through interactions between $\alpha 2,3-$ 
linked sialic acids expressed on B-cell-exosomes and sialoadhesin (CD169) expressed on macrophages (Saunderson et al. 2014). EVs secreted by most cells show limited tropism to a specific cells type, however, and therefore targeting strategies for systemically delivered EVs are required (Figure 2).

Targeting exosomes to a given cell type can be accomplished by displaying a ligand on the outer surface of exosomes by inserting the coding sequence of the ligand in-frame to the coding sequences between the signal peptide and $\mathrm{N}$-terminus of the mature peptide of a transmembrane protein (Alvarez-Erviti et al. 2011; Cooper et al. 2014). For short peptide targeting, this can be achieved by a two-step overlapping DNA polymerase chain reaction (PCR), followed by the insertion of the fused open reading frame (ORF) cassette into a bicistronic lentiviral expression plasmid, and transduction of producer cells. The released EVs will bear the ligand/homing peptide on their surface (Xitong \& Xiaorong 2016). Because biological ligands fused with one of the membrane proteins form large molecules, however, poor expression or folding of these fusion proteins, or incorrect display of the targeting protein on the exosome surface remain of potential concern. Core ligand fragments (for known receptors) or homing peptides (for unknown receptors) are smaller than natural ligands, and therefore may be preferable for surface display on exosomes. Novel core ligand fragments and homing peptides have been discovered by phage display (Smith 1985). The identification of homing peptides that bind to unknown receptors requires in vivo biopanning (Costantini et al. 2012). Examples of naturally occurring homing peptides include EBV gp350, which targets B cells via interaction with the $B$ lineage marker CD21, and rabies viral glycoprotein (RVG), which targets acetylcholine receptors on neurons. The cotransfer of functional CD154 (CD40 ligand) protein, which activates immune cells through the CD40 receptor, on tailored gp350-positive exosomes to malignant B blasts from patients with B chronic lymphocytic leukaemia induced blast immunogenicity to tumour-reactive autologous T cells (Ruiss et al. 2011). Examples of synthetic peptides targeting known receptors include GE11 peptide, which targets EGFR (Li et al. 2005), and iRGD (internalising arginine-glycine-asparagine) peptide, which targets integrins and neuropilins (Pang et al. 2014; Yu et al. 2013). GE11-targeted exosomes were taken up more efficiently than untargeted exosomes by EGFR-positive human tumour grafts in mice (Ohno et al. 2013a; Ohno et al. 2013b). Both targeted and untargeted exosomes accumulated in the liver, however, indicating that targeting did not prevent off-target delivery. Peptides targeting unknown receptors on intended tissues have also been identified (Lee et al. 2015; Thapa et al. 2008).

The three transmembrane proteins that have been used widely in exosome targeting are LAMP-2b, lactadherin, and platelet-derived growth factor receptors (PDGFRs). Engineered immature DCs expressing a fusion construct of the iRGD peptide and LAMP-2b released iRGD-targeted EVs. Upon loading with 
doxorubicin by electroporation, iRGD-targeted EVs delivered doxorubicin selectively to breast cancer xenografts, reduced tumour growth in mice, and caused less drug-induced cardiac toxicity compared with untargeted EVs (Tian et al. 2014). The latter were taken up primarily by the liver and spleen, and did not reduce tumour growth. Exosomes released from DCs expressing a fusion construct of the RVG peptide and LAMP-2B were detected specifically in neurons, microglia, and oligodendrocytes in the mouse brain (Alvarez-Erviti et al. 2011). The efficiency of RVG-targeted exosomes was limited by enzymatic cleavage of the signal peptide. The introduction of a glycosylation motif into this peptide improved exosome delivery to neuroblastoma cells in vivo (Hung \& Leonard 2015).

When the coding sequence of a targeting peptide is inserted in-frame in-between the coding sequences of the signal peptide and the $\mathrm{C} 1 \mathrm{C} 2$ domain of lactadherin, and the fusion cassette is expressed in cells using a gene transfer vector, the secreted exosomes will display the targeting peptide on their surface. Chinese hamster ovary cells transfected with fusion constructs of C1C2 and IL-2 or granulocyte/monocyte colonystimulating factor (GM-CSF) released exosomes enriched in the recombinant cytokines (Delcayre et al. 2005). Murine fibrosarcoma cells engineered to express a fusion construct of C1C2 and chicken egg ovalbumin (OVA) antigen secreted exosome-bound OVA and grew slower than tumour cells that secreted soluble OVA in mice, indicating that exosome-bound antigen outperformed soluble antigen in immunostimulatory efficacy (Zeelenberg et al. 2008). A recent study compared two approaches to associate OVA antigen to EVs: by fusion to the C1C2 domain of lactadherin, which is exposed on the EV surface, or by fusion to retroviral Gag capsid protein, which is incorporated inside membrane-enclosed virus-like particles (Sedlik et al. 2014). Both DNA vaccines induced OVA-specific CD8 ${ }^{+} \mathrm{T}$ cells and total IgG antibodies with comparable efficiency, and reduced in vivo progression of OVA-expressing tumours in mice. The OVAC1C2-encoding vaccine, but not the the Gag-OVA vaccine, preferentially stimulated antigen-specific $\mathrm{CD}^{+}{ }^{+}$ cells. To facilitate antigen cross-presentation, human EGFR-2, carcinoembryonic antigen (Hartman et al. 2011), prostate-specific antigen, or prostatic acid phosphatase (Rountree et al. 2011) were displayed on the exosome surface by lactadherin coupling. Exosomes displaying either prostate antigen inhibited prostate cancer growth. Lactadherin-mediated display of somatostatin receptor-2, a G protein-coupled receptor, on the exosome surface was used for drug screening (Estelles el al. 2007).

Alternatively, EV surfaces can be coated with antibody fragments recognizing antigens expressed on target cells (Pasquetto et al. 2011). Exosome-like nanovesicles coated with antigen-specific antibody light chains targeting effector $T$ cells successfully delivered immunosuppressive miRNA-150 from suppressor $\mathrm{CD}^{+} \mathrm{T}$ cells to effector T cells, and induced antigen-specific inhibition of contact sensitivity (Bryniarski et al. 2013). 
Most recently, EV-producing cells were transfected with vectors encoding anti-EGFR nanobodies fused to glycosylphosphatidylinositol (GPI) anchor signal peptides to target EGFR expressing tumour cells (Kooijmans et al. 2016). Display of GPI-linked nanobodies on EVs greatly enhanced binding to tumour cells dependent on EGFR density. GPI-anchoring may provide a valuable strategy for EV display of a variety of proteins including antibodies, reporter proteins, and signaling molecules.

Apart from targeting peptides, peptides that indiscriminately facilitate the uptake of EVs, such as vesicular stomatitis virus-G (VSV-G) protein, can be displayed on EVs. VSV-G displaying EVs achieved improved cargo delivery and therapeutic immune responses to exosomal vaccines (Temchura et al. 2008).

\section{Artificial exosome mimetics}

All strategies outlined above relay on naturally secreted EVs with no or limited modifications to their composition. However, exosomes exhibit complex structures that are difficult to characterize pharmaceutically. Their composition varies with the producer cell type and its physiological state, as well as with manufacturing protocols. The purification of single populations of EVs is a complex procedure. While pure populations of exosomes can be isolated from exosome-secreting cell lines, these exosomes, unlike those released from autologous primary cells, have immunogenic and oncogenic potential. Moreover, EVs play multifaceted roles in health and disease, including the intercellular transfer of pathogens and diseaseassociated proteins, which are far from being understood (Camussi et al. 2011; Meckes \& Raab-Traub 2011; Saa et al. 2014). These features represent major barriers for translation of naturally secreted exosomes to the clinic. Engineered exosome mimetics may help circumvent these barriers (van der Meel et al. 2014). Synthetic lipid vesicles (liposomes) share with natural exosomes a spherical phospholipid bilayer structure about $100 \mathrm{~nm}$ in diameter, which can serve as a primitive structure for exosome mimetics (Kooijmans et al. 2012). Liposomes can be loaded with exosomal components, to mimic naturally occurring exosomes, and with therapeutic molecules including recombinant proteins, nucleic acids, and synthetic drugs (Malam et al. 2009). Therapeutics based on liposomes and nanoparticles have been approved for clinical applications (Fenske \& Cullis 2008). The lipid composition of liposomes can be modulated. Phosphatidylserine represents a good candidate component of exosome mimetics, as it contributes to the stability and uptake of natural exosomes while also regulating DC maturation (Chen et al. 2004). Addition of cholesterol to pure phosphatidylserine vesicles may enhance cation-induced fusion (Shavnin et al. 1988). Addition of a shortchain glucosylceramide to liposomes composed of hydrogenated soy phosphatidylcholine, cholesterol, and distearylphosphatidylethanolamine-PEG2000 improved doxorubicin delivery and anti-tumour effects in mice 
(van Lummel et al. 2011). Interestingly, lipids purified from intestine-derived EV-like nanoparticles and reconstituted into liposomes conferred the NK T-cell inhibitory activities of the original nanoparticles to the liposomes (Deng et al. 2013). Incorporation of functional membrane proteins into liposomes has been reported (Aimon et al. 2011; Erb et al. 1997; Varnier et al. 2010). However, loading liposomes with multiple proteins or high amounts of siRNA or miRNA remains a difficult task (Lakhal \& Wood 2011). In a proof-ofconcept study, FDA-approved liposomes coated with an optimized number of MHC-1/peptide complexes and a selected specific range of ligands for adhesion, activation, and survival induced activation and expansion of functional antigen-specific T cells in vitro and in vivo (De La Peña et al. 2009).

\section{Immune responses to exosomes}

Unlike viral gene transfer vectors or liposomes (Seow \& Wood 2009), autologous exosomes show negligible immunogenicity. Repeated i.v. injections of autologous exosomes from immature DCs did not trigger significant immune responses in mice (Alvarez-Erviti et al. 2011). However, therapeutic applications for acute clinical events (e.g., myocardial infarction) would require ready-to-use exosome preparations in storage. Frozen exosome preparations can be stored for extended periods of time without major losses in functional activity. Stored exosome preparations are most easily derived from allogeneic donor cells. However, the creation of autologous exosome banks, in analogy to autologous stem cell banks, is theoretically conceivable, although this option would be impractical, expensive, and possibly unnecessary. Exosomes from allogeneic donor cells offer several potential advantages over autologous ones. Exosomes derived from cells of young, healthy donors might show superior functional activities compared to exosomes from old or ill patients, although this remains to be demonstrated. Age- and disease-dependent functional differences have been reported for cells used in cell therapy (Zhuo et al. 2010). Another potential advantage of allogeneic exosomes is that a large number of batches of the medicinal product can be derived from the cells of a single donor. As a result, many patients can be treated with the same product, which eases the evaluation of many parameters, e.g., interindividual variability, dosing effects, safety, and efficacy. Whether allogeneic exosomes can be safely used in human is a crucial yet unanswered question.

Naturally secreted exosomes express immune recognition molecules including functional MHC-I and/or MHC-II depending on their cellular origin (Caby et al. 2005; Lynch et al. 2009). Experimental evidence suggests that allogeneic exosomes may be hypo-immunogenic and well tolerated in many circumstances. A single systemic administration of exosomes from BALB/c donor DCs failed to activate splenic DCs in B10 recipient mice (Morelli et al. 2004). A recent study investigated the immunogenicity of EVs secreted by 
xenogeneic (human) or allogeneic cardiosphere-derived cells. Repeated subcutaneous injections of EVs derived from the human cells induced progressive humoral and cell-mediated immune responses, as expected, although at lower levels compared to injections of their parent cells (Mirotsou M 2015). Allogeneic EVs did not induce significant immune responses after repeated dosing. These findings suggest that allogeneic EVs may be suitable for clinical applications. Future studies will need to address not only immune responses to exosomes from allogeneic donors but also risks of inflammation, induction of autoimmunity, and transfer of pathogens including endogenous retroviruses (Gould et al. 2003).

\section{Experience in clinical trials}

The safety of EV-based anti-tumour and anti-bacterial vaccines was tested in several phase-I clinical trials and one phase-II trial. In a phase-I trial, DCs of patients with advanced melanoma were isolated and pulsed with tumour antigen. Exosomes presenting the tumour antigen were purified and injected intradermally and subcutaneously to the patients. Exosome administration was tolerated for up to 21 months. A mild inflammatory reaction at the site of injection was observed in some patients. One of 15 patients exhibited a specific melanoma antigen T cell-response and a reduction in tumour size (Escudier et al. 2005). Another phase-I trial involved the administration of EVs from autologous DCs pulsed with melanoma antigen gene (MAGE) peptides to patients bearing non-small cell lung cancer. EVs administered weekly for 4 weeks were well-tolerated. One-third of patients exhibited MAGE-specific T-cell responses (Morse et al. 2005). A distinct phase-I trial evaluated EVs isolated from autologous ascites fluid in patients bearing colo-rectal cancer, with or without GM-CSF treatment. Mild inflammation at the site of injection was observed. Eighty percent of patients receiving combined EV/GM-CSF therapy showed cytotoxic T-cell responses to colon cancer peptide CAP-1, with one clinical stabilisation and one minor response (Dai et al. 2008). Another phase-I trial showed that serogroup B meningococcal outer membrane vesicle vaccines were safe and effective (Sandbu et al. 2007). A recent phase-II trial evaluated IFNY-DC-derived exosomes loaded with $\mathrm{MHC} \mathrm{I} / \mathrm{II}$ restricted cancer antigens as maintenance immunotherapy after induction chemotherapy in patients bearing inoperable nonsmall cell lung cancer without tumour progression (Besse et al. 2016). The primary endpoint was to observe at least $50 \%$ of patients with progression-free survival at 4 months after chemotherapy cessation. Twentytwo patients received the therapy. One patient exhibited a grade-III hepatotoxicity. Seven patients (32\%) experienced stabilization of more than 4 months; thus, the primary endpoint was not reached. These results suggest that DC-derived exosome vaccines may be safe and may promote $\mathrm{T}$ and NK cell responses in patients (Pitt et al. 2016). Planned or ongoing therapeutic studies are listed in Table 2. Several study are 
focused on cancer. One study addresses the effects of plasma-derived exosomes on cutaneous wound healing. Another study evaluates microvesicles and exosomes therapy on $\beta$-cell mass in type- 1 diabetes mellitus.

\section{Conclusion}

As mediators of intercellular communication, EVs can be harnessed for both diagnostic and therapeutic purposes. While naturally secreted exosomes may mediate beneficial effects in certain disease conditions, targeted exosomes loaded with therapeutic molecules may optimize efficacy while also reducing off-target delivery. Therapeutic molecules may include biological molecules that are difficult to deliver intracellularly without the use of a carrier, such as miRNA, siRNA and recombinant proteins, as well as synthetic smallmolecule drugs. EV isolation and characterization protocols are moving toward clinical applications (Xu et al. 2016). DC-derived EVs have been shown to be safe in phase-I/II clinical trials in cancer patients. However, the complex structure and the variable composition and functional activity of naturally secreted exosomes may limit their pharmaceutical acceptability. A potential alternative is the development of exosome mimetics manufactured using clinical-grade, purified synthetic lipids and recombinant proteins, and assembled using controllable procedures. Selected components of natural exosomes can be incorporated into liposomes or nanoparticles to enhance stability, immunogenicity, targeting, and uptake. However, the precise components of natural exosomes that are critical for therapeutic delivery have not been pinpointed yet.

\section{Acknowledgments}

G.V. and L.B. are the recipients of a research grant by the Swiss National Science Foundation.

\section{Conflict of Interest}

Authors declare that there are no conflicts of interest.

On behalf of my co-author, Giuseppe Vassalli, I declare that

authors do not have any actual or potential conflict of interest including any financial, personal or other relationships with individuals or organizations within three years of initiating the work that could inappropriately influence, or be perceived to influence, the study design or data interpretation. 


\section{References}

Aimon, S., J. Manzi, D. Schmidt, J. A. Poveda Larrosa, P. Bassereau \& G. E. Toombes: Functional reconstitution of a voltage-gated potassium channel in giant unilamellar vesicles. PLoS One 2011, 6, e25529.

Alexander, M., R. Hu, M. C. Runtsch, D. A. Kagele, T. L. Mosbruger, T. Tolmachova, M. C. Seabra, J. L. Round, D. M. Ward \& R. M. O'Connell: Exosome-delivered microRNAs modulate the inflammatory response to endotoxin. Nat Comm 2015, 7321, 1-15.

Al-Nedawi, K., B. Meehan, R. S. Kerbel, A. C. Allison \& J. Rak: Endothelial expression of autocrine VEGF upon the uptake of tumor-derived microvesicles containing oncogenic EGFR. Proc Natl Acad Sci U S A 2009, 106, 3794-9.

Al-Nedawi, K., B. Meehan, J. Micallef, V. Lhotak, L. May, A. Guha \& J. Rak: Intercellular transfer of the oncogenic receptor EGFRvill by microvesicles derived from tumour cells. Nat Cell Biol 2008, 10, 619-24.

Alvarez-Erviti, L., Y. Seow, H. Yin, C. Betts, S. Lakhal \& M. J. Wood: Delivery of siRNA to the mouse brain by systemic injection of targeted exosomes. Nat Biotechnol 2011, 29, 341-5.

Andaloussi, S., I. Mager, X. O. Breakefield \& M. J. Wood: Extracellular vesicles: biology and emerging therapeutic opportunities. Nat Rev Drug Discov 2013, 12, 347-57.

Baglio, S. R., D. M. Pegtel \& N. Baldini: Mesenchymal stem cell secreted vesicles provide novel opportunities in (stem) cell-free therapy. Front Physiol 2012, 3, 359.

Baietti, M. F., Z. Zhang, E. Mortier, A. Melchior, G. Degeest, A. Geeraerts, Y. Ivarsson, F. Depoortere, C. Coomans, E. Vermeiren, P. Zimmermann \& G. David: Syndecan-syntenin-ALIX regulates the biogenesis of exosomes. Nat Cell Biol 2012, 14, 677-85.

Bakela, K., N. Kountourakis, M. Aivaliotis \& I. Athanassakis: Soluble MHC-II proteins promote suppressive activity in CD4+ T cells. Immunology 2015, 144, 158-69.

Barile, L., V. Lionetti, E. Cervio, M. Matteucci, M. Gherghiceanu, L. M. Popescu, T. Torre, F. Siclari, T. Moccetti \& G. Vassalli: Extracellular vesicles from human cardiac progenitor cells inhibit cardiomyocyte apoptosis and improve cardiac function after myocardial infarction. Cardiovasc Res 2014, 103, 530-41.

Besse, B., M. Charrier, V. Lapierre, E. Dansin, O. Lantz, D. Planchard, T. Le Chevalier, A. Livartoski, F. Barlesi, A. Laplanche, S. Ploix, N. Vimond, I. Peguillet, C. Théry, L. Lacroix, I. Zoernig, K. Dhodapkar, M. Dhodapkar, S. Viaud, J. C. Soria, K. S. Reiners, E. Pogge von Strandmann, F. Vély, S. Rusakiewicz, A. Eggermont, J. M. Pitt, L. Zitvogel \& N. Chaput: Dendritic cell-derived exosomes as maintenance immunotherapy after first line chemotherapy in NSCLC. Oncoimmunology 2015, 5, e1071008.

Bianco, N. R., S. H. Kim, A. E. Morelli \& P. D. Robbins: Modulation of the immune response using dendritic cell-derived exosomes. Methods Mol Biol 2007, 380, 443-55.

Blanchard, N., D. Lankar, F. Faure, A. Regnault, C. Dumont, G. Raposo \& C. Hivroz: TCR activation of human $T$ cells induces the production of exosomes bearing the TCR/CD3/zeta complex. $J$ Immunol 2002, 168, 3235-41.

Bruno, S., C. Grange, M. C. Deregibus, R. A. Calogero, S. Saviozzi, F. Collino, L. Morando, A. Busca, M. Falda, B. Bussolati, C. Tetta \& G. Camussi: Mesenchymal stem cell-derived microvesicles protect against acute tubular injury. J Am Soc Nephrol 2009, 20, 1053-67.

Bryniarski, K., W. Ptak, A. Jayakumar, K. Pullmann, M. J. Caplan, A. Chairoungdua, J. Lu, B. D. Adams, E. Sikora, K. Nazimek, S. Marquez, S. H. Kleinstein, P. Sangwung, Y. Iwakiri, E. Delgato, F. Redegeld, B. R. Blokhuis, J. Wojcikowski, A. W. Daniel, T. Groot Kormelink \& P. W. Askenase: Antigenspecific, antibody-coated, exosome-like nanovesicles deliver suppressor T-cell microRNA-150 to effector T cells to inhibit contact sensitivity. J Allergy Clin Immunol 2013, 132, 170-81.

Budnik, V., C. Ruiz-Cañada \& F. Wendler: Extracellular vesicles round off communication in the nervous system. Nat Rev Neurosci 2016, 17, 160-72.

Buschow, S. I., E. N. Nolte-'t Hoen, G. van Niel, M. S. Pols, T. ten Broeke, M. Lauwen, F. Ossendorp, C. J. Melief, G. Raposo, R. Wubbolts, M. H. Wauben \& W. Stoorvogel: MHC II in dendritic cells is targeted to lysosomes or T cell-induced exosomes via distinct multivesicular body pathways. Traffic 2009, 10,1528-42.

Buzas, E. I., B. Gyorgy, G. Nagy, A. Falus \& S. Gay: Emerging role of extracellular vesicles in inflammatory diseases. Nat Rev Rheumatol 2014, 10, 356-64.

Caby, M. P., D. Lankar, C. Vincendeau-Scherrer, G. Raposo \& C. Bonnerot: Exosomal-like vesicles are present in human blood plasma. Int Immunol 2005, 17, 879-87.

Camussi, G., M. C. Deregibus, S. Bruno, C. Grange, V. Fonsato \& C. Tetta: Exosome/microvesicle-mediated epigenetic reprogramming of cells. Am J Cancer Res 2011, 1, 98-110. 
Cantaluppi, V., S. Gatti, D. Medica, F. Figliolini, S. Bruno, M. C. Deregibus, A. Sordi, L. Biancone, C. Tetta \& G. Camussi: Microvesicles derived from endothelial progenitor cells protect the kidney from ischemia-reperfusion injury by microRNA-dependent reprogramming of resident renal cells. Kidney Int 2012, 82, 412-27.

Castanotto, D. \& J. J. Rossi: The promises and pitfalls of RNA-interference-based therapeutics. Nature 2009, 457, 426-33.

Chen, X., K. Doffek, S. L. Sugg \& J. Shilyansky: Phosphatidylserine regulates the maturation of human dendritic cells. J Immunol 2004, 173, 2985-94.

Cheng, Y. \& J. S. Schorey: Exosomes carrying mycobacterial antigens can protect mice against Mycobacterium tuberculosis infection. Eur J Immunol 2013, 43, 3279-90.

Chevillet, J. R., Q. Kang, I. K. Ruf, H. A. Briggs, L. N. Vojtech, S. M. Hughes, H. H. Cheng, J. D. Arroyo, E. K. Meredith, E. N. Gallichotte, E. L. Pogosova-Agadjanyan, C. Morrissey, D. L. Stirewalt, F. Hladik, E. Y. Yu, C. S. Higano \& M. Tewari: Quantitative and stoichiometric analysis of the microRNA content of exosomes. Proc Natl Acad Sci U S A 2014, 111, 14888-93.

Chitadze, G., M. Lettau, J. Bhat, D. Wesch, A. Steinle, D. Fürst, J. Mytilineos, H. Kalthoff, O. Janssen, H. H. Oberg \& D. Kabelitz: Shedding of endogenous MHC class I-related chain molecules A and B from different human tumor entities: heterogeneous involvement of the "a disintegrin and metalloproteases" 10 and 17. Int J Cancer 2013, 133, 1557-66.

Cho, J. A., H. Park, E. H. Lim, K. H. Kim, J. S. Choi, J. H. Lee, J. W. Shin \& K. W. Lee: Exosomes from ovarian cancer cells induce adipose tissue-derived mesenchymal stem cells to acquire the physical and functional characteristics of tumor-supporting myofibroblasts. Gynecol Oncol 2011, 123, 379-86.

Choi, D. S., D. K. Kim, Y. K. Kim \& Y. S. Gho: Proteomics, transcriptomics and lipidomics of exosomes and ectosomes. Proteomics 2013, 13, 1554-71.

Choudhuri, K., J. Llodra, E. W. Roth, J. Tsai, S. Gordo, K. W. Wucherpfennig, L. C. Kam, D. L. Stokes \& M. L. Dustin: Polarized release of T-cell-receptor-enriched microvesicles at the immunological synapse. Nature 2014, 507, 118-23.

Christianson, H. C., K. J. Svensson, T. H. van Kuppevelt, J.-P. Li \& M. Belting: Cancer cell exosomes depend on cell-surface heparan sulfate proteoglycans for their internalization and functional activity. Proc Natl Acad Sci U S A 2013, 110, 17380-5.

Chugh, P. E., S. H. Sin, S. Ozgur, D. H. Henry, P. Menezes, J. Griffith, J. J. Eron, B. Damania \& D.P. Dittmer: Systemically circulating viral and tumor-derived microRNAs in KSHV-associated malignancies. PLoS Pathog 2013, 9, e1003484.

Clayton, A., C. L. Harris, J. Court, M. D. Mason \& B. P. Morgan: Antigen-presenting cell exosomes are protected from complement-mediated lysis by expression of CD55 and CD59. Eur J Immunol 2003, 33, 522-31.

Clayton, A., A. Turkes, H. Navabi, M. D. Mason \& Z. Tabi: Induction of heat shock proteins in B-cell exosomes. J Cell Sci 2005, 118, 3631-8.

Cline, A. M. \& M. Z. Radic: Apoptosis, subcellular particles, and autoimmunity. Clin Immunol 2004, 112, 17582.

Coleman, B. M. \& A. F. Hill: Extracellular vesicles--Their role in the packaging and spread of misfolded proteins associated with neurodegenerative diseases. Semin Cell Dev Biol 2015, 40, 89-96.

Colino, J. \& C. M. Snapper: Exosomes from bone marrow dendritic cells pulsed with diphtheria toxoid preferentially induce type 1 antigen-specific IgG responses in naive recipients in the absence of free antigen. J Immunol 2006, 177, 3757-62.

Colombo, M., C. Moita, G. van Niel, J. Kowal, J. Vigneron, P. Benaroch, N. Manel, L. F. Moita, C. Théry \& G. Raposo G: Analysis of ESCRT functions in exosome biogenesis, composition and secretion highlights the heterogeneity of extracellular vesicles. J Cell Sci 2013, 126(Pt 24), 5553-65.

Cooper, J. M., P. B. Wiklander, J. Z. Nordin, R. Al-Shawi, M. J. Wood, M. Vithlani, A. H. Schapira, J. P. Simons, S. El-Andaloussi \& L. Alvarez-Erviti: Systemic exosomal siRNA delivery reduced alphasynuclein aggregates in brains of transgenic mice. Mov Disord 2014, 29, 1476-85.

Costa-Silva, B., N. M. Aiello, A. J. Ocean, S. Singh, H. Zhang, B. K. Thakur, A. Becker, A. Hoshino, M. T. Mark, H. Molina, J. Xiang, T. Zhang, T. M. Theilen, G. Garcia-Santos, C. Williams, Y. Ararso, Y. Huang, G. Rodrigues, T. L. Shen, K. J. Labori, I. M. Lothe, E. H. Kure, J. Hernandez, A. Doussot, S. H. Ebbesen, P. M. Grandgenett, M. A. Hollingsworth, M. Jain, K. Mallya, S. K. Batra, W. R. Jarnagin, R. E. Schwartz, I. Matei, H. Peinado, B. Z. Stanger, J. Bromberg \& D. Lyden: Pancreatic cancer exosomes initiate pre-metastatic niche formation in the liver. Nat Cell Biol 2015, 17, 816-26.

Costantini, T.W., B.P. Eliceiri, J.G.Putnam, V. Bansal, A. Baird \& R. Coimbra: Intravenous phage display identifies peptide sequences that target the burn-injured intestine. Peptides 2012, 38, 94-9.

Dai, S., D. Wei, Z. Wu, X. Zhou, X. Wei, H. Huang \& G. Li: Phase I clinical trial of autologous ascites-derived exosomes combined with GM-CSF for colorectal cancer. Mol Ther 2008, 16, 782-90. 
de Curtis, I. \& J. Meldolesi: Cell surface dynamics - how Rho GTPases orchestrate the interplay between the plasma membrane and the cortical cytoskeleton. J Cell Sci 2012, 125, 4435-44.

de Jong, O. G., M. C. Verhaar, Y. Chen, P. Vader, H. Gremmels, G. Posthuma, R. M. Schiffelers, M. Gucek \& B. W. van Balkom: Cellular stress conditions are reflected in the protein and RNA content of endothelial cell-derived exosomes. J Extracell Vesicles 2012, 1, 18396.

De La Peña, H., J. A. Madrigal, S. Rusakiewicz, M. Bencsik, G. W. Cave, A. Selman, R. C. Rees, P. J. Travers \& I. A. Dodi: Artificial exosomes as tools for basic and clinical immunology. J Immunol Methods 2009, 344, 121-32.

de Rivero Vaccari, J. P., F. Brand, 3rd, S. Adamczak, S. W. Lee, J. P. Barcena, M. Y. Wang, M. R. Bullock, W. D. Dietrich \& R. W. Keane: Exosome-mediated inflammasome signaling after central nervous system injury. J Neurochem 2015.

Delcayre, A., A. Estelles, J. Sperinde, T. Roulon, P. Paz, B. Aguilar, J. Villanueva, S. Khine \& J. B. Le Pecq: Exosome display technology: applications to the development of new diagnostics and therapeutics. Blood Cells Mol Dis 2005, 35, 158-68.

Delorme-Axford, E., R. B. Donker, J. F. Mouillet, T. Chu, A. Bayer, Y. Ouyang, T. Wang, D. B. Stolz, S. N. Sarkar, A. E. Morelli, Y. Sadovsky \& C. B. Coyne: Human placental trophoblasts confer viral resistance to recipient cells. Proc Natl Acad Sci U S A 2013, 110, 12048-53.

Deng, Z. B., X. Zhuang, S. Ju, X. Xiang, J. Mu, Y. Liu, H. Jiang, L. Zhang, J. Mobley, C. McClain, W. Feng, W. Grizzle, J. Yan, D. Miller, M. Kronenberg \& H. G. Zhang: Exosome-like nanoparticles from intestinal mucosal cells carry prostaglandin E2 and suppress activation of liver NKT cells. $J$ Immunol 2013, 190, 3579-89.

Denzer, K., M. J. Kleijmeer, H. F. Heijnen, W. Stoorvogel \& H. J. Geuze: Exosome: from internal vesicle of the multivesicular body to intercellular signaling device. J Cell Sci 2000, $113 \mathrm{Pt} \mathrm{19,3365-74.}$

Deregibus, M. C., V. Cantaluppi, R. Calogero, M. Lo lacono, C. Tetta, L. Biancone, S. Bruno, B. Bussolati \& G. Camussi: Endothelial progenitor cell derived microvesicles activate an angiogenic program in endothelial cells by a horizontal transfer of mRNA. Blood 2007, 110, 2440-8.

Doeppner, T. R., J. Herz, A. Gorgens, J. Schlechter, A. K. Ludwig, S. Radtke, K. de Miroschedji, P. A. Horn, B. Giebel \& D. M. Hermann: Extracellular Vesicles Improve Post-Stroke Neuroregeneration and Prevent Postischemic Immunosuppression. Stem Cells Transl Med 2015, 4, 1131-43.

Duijvesz, D., K. E. Burnum-Johnson, M. A. Gritsenko, A. M. Hoogland, M. S. Vredenbregt-van den Berg, R. Willemsen, T. Luider, L. Pasa-Tolic \& G. Jenster: Proteomic profiling of exosomes leads to the identification of novel biomarkers for prostate cancer. PLoS One 2013, 8, e82589.

Erb, E. M., K. Tangemann, B. Bohrmann, B. Muller \& J. Engel: Integrin alphallb beta3 reconstituted into lipid bilayers is nonclustered in its activated state but clusters after fibrinogen binding. Biochemistry 1997, 36, 7395-402.

Escudier, B., T. Dorval, N. Chaput, F. Andre, M. P. Caby, S. Novault, C. Flament, C. Leboulaire, C. Borg, S. Amigorena, C. Boccaccio, C. Bonnerot, O. Dhellin, M. Movassagh, S. Piperno, C. Robert, V. Serra, N. Valente, J. B. Le Pecq, A. Spatz, O. Lantz, T. Tursz, E. Angevin \& L. Zitvogel: Vaccination of metastatic melanoma patients with autologous dendritic cell (DC) derived-exosomes: results of thefirst phase I clinical trial. J Trans/ Med 2005, 3, 10.

Estelles, A., J. Sperinde, T. Roulon, B. Aguilar, C. Bonner, J. B. LePecq \& A. Delcayre: Exosome nanovesicles displaying G protein-coupled receptors for drug discovery. Int J Nanomedicine 2007, 2, 751-60.

Faure, J., G. Lachenal, M. Court, J. Hirrlinger, C. Chatellard-Causse, B. Blot, J. Grange, G. Schoehn, Y. Goldberg, V. Boyer, F. Kirchhoff, G. Raposo, J. Garin \& R. Sadoul: Exosomes are released by cultured cortical neurones. Mol Cell Neurosci 2006, 31, 642-8.

Feliciano, D. M., S. Zhang, C. M. Nasrallah, S. N. Lisgo \& A. Bordey: Embryonic cerebrospinal fluid nanovesicles carry evolutionarily conserved molecules and promote neural stem cell amplification. PLoS One 2014, 9, e88810.

Feng, Z., L. Hensley, K. L. McKnight, F. Hu, V. Madden, L. Ping, S. H. Jeong, C. Walker, R. E. Lanford \& S. M. Lemon: A pathogenic picornavirus acquires an envelope by hijacking cellular membranes. Nature 2013, 496, 367-71.

Fenske, D. B. \& P. R. Cullis: Liposomal nanomedicines. Expert Opin Drug Deliv 2008, 5, 25-44.

Février, B. \& G. Raposo: Exosomes: endosomal-derived vesicles shipping extracellular messages. Curr Opin Cell Biol 2004, 16, 415-21.

Fitzner, D., M. Schnaars, D. van Rossum, G. Krishnamoorthy, P. Dibaj, M. Bakhti, T. Regen, U. K. Hanisch \& M. Simons: Selective transfer of exosomes from oligodendrocytes to microglia by macropinocytosis. J Cell Sci 2011, 124(Pt 3), 447-58.

Fruhbeis, C., D. Frohlich \& E. M. Kramer-Albers: Emerging roles of exosomes in neuron-glia communication. Front Physiol 2012, 3, 119. 
Futter, C. E., A. Pearse., L. J. Hewlett \& C. R Hopkins: Multivesicular endosomes containing internalized EGF-EGF receptor complexes mature and then fuse directly with lysosomes. J Cell Biol 1996, 132, 1011-23.

Gibbings, D. J., C. Ciaudo, M. Erhardt \& O. Voinnet: Multivesicular bodies associate with components of miRNA effector complexes and modulate miRNA activity. Nat Cell Biol 2009, 11, 1143-9.

Goetzl, E. J., A. Boxer, J. B. Schwartz, E. L. Abner, R. C. Petersen, B. L. Miller \& D. Kapogiannis: Altered lysosomal proteins in neural-derived plasma exosomes in preclinical Alzheimer disease. Neurology 2015, 85, 40-7.

Gould, S. J., A. M. Booth \& J. E. Hildreth: The Trojan exosome hypothesis. Proc Natl Acad Sci U S A 2003, 100, $10592-7$.

Graves, L. E., E. V. Ariztia, J. R. Navari, H. J. Matzel, M. S. Stack \& D. A. Fishman: Proinvasive properties of ovarian cancer ascites-derived membrane vesicles. Cancer Res 2004, 64, 7045-9.

Gregory, C. D. \& J. D. Pound: Microenvironmental influences of apoptosis in vivo and in vitro. Apoptosis 2010, 15, 1029-49.

Gross, J.C., V. Chaudhary, K. Bartscherer \& M. Boutros: Active Wnt proteins are secreted on exosomes. Nat Cell Biol 2012, 14, 1036-45.

Guo, B. B., S. A. Bellingham \& A. F. Hill: The neutral sphingomyelinase pathway regulates packaging of the prion protein into exosomes. J Biol Chem 2015, 290, 3455-67.

Guo, P., O. Coban, N. M. Snead, J. Trebley, S. Hoeprich, S. Guo \& Y. Shu: Engineering RNA for targeted siRNA delivery and medical application. Adv Drug Deliv Rev 2010, 62, 650-66.

Gupta, A. \& L. Pulliam: Exosomes as mediators of neuroinflammation. J Neuroinflammation 2014, 11, 68.

Gupta, S. \& A. A. Knowlton: HSP60 trafficking in adult cardiac myocytes: role of the exosomal pathway. Am J Physiol Heart Circ Physiol 2007, 292, H3052-6.

György, B., M. E. Hung, X. O. Breakefield \& J. N. Leonard: Therapeutic applications of extracellular vesicles: clinical promise and open questions. Annu Rev Pharmacol Toxicol 2015, 55, 439-64.

Haney, M. J., N. L. Klyachko, Y. Zhao, R. Gupta, E. G. Plotnikova, Z. He, T. Patel, A. Piroyan, M. Sokolsky, A. V. Kabanov \& E. V. Batrakova: Exosomes as drug delivery vehicles for Parkinson's disease therapy. J Control Release 2015, 207, 18-30.

Hartman, Z. C., J. Wei, O. K. Glass, H. Guo, G. Lei, X. Y. Yang, T. Osada, A. Hobeika, A. Delcayre, J. B. Le Pecq, M. A. Morse, T. M. Clay \& H. K. Lyerly: Increasing vaccine potency through exosome antigen targeting. Vaccine 2011, 29, 9361-7.

Heusermann, W., J. Hean, D. Trojer, E. Steib, S. von Bueren, A. Graff-Meyer, C. Genoud, K. Martin, N. Pizzato, J. Voshol, D. V. Morrissey, S. E. Andaloussi, M. J. Wood \& N. C. Meisner-Kober: Exosomes surf on filopodia to enter cells at endocytic hot spots, traffic within endosomes, and are targeted to the ER. J Cell Biol 2016, 213, 173-84.

Higginbotham, J. N., M. Demory Beckler, J. D. Gephart, J. L. Franklin, G. Bogatcheva, G. J. Kremers, D. W. Piston, G. D. Ayers, R. E. McConnell, M. J. Tyska \& R. J. Coffey: Amphiregulin exosomes increase cancer cell invasion. Curr Biol 2011, 21, 779-86.

Hoefer, I. E., S. Steffens, M. Ala-Korpela, M. Back, L. Badimon, M. L. Bochaton-Piallat, C. M. Boulanger, G. Caligiuri, S. Dimmeler, J. Egido, P. C. Evans, T. Guzik, B. R. Kwak, U. Landmesser, M. Mayr, C. Monaco, G. Pasterkamp, J. Tunon \& C. Weber: Novel methodologies for biomarker discovery in atherosclerosis. Eur Heart $J 2015$.

Hood, J. L., H. Pan, G. M. Lanza \& S. A. Wickline: Paracrine induction of endothelium by tumor exosomes. Lab Invest 2009, 89, 1317-28.

Hoshino, D., K. C. Kirkbride, K. Costello, E.S. Clark, S. Sinha, N. Grega-Larson, M. J. Tyska \& A. M. Weaver: Exosome secretion is enhanced by invadopodia and drives invasive behavior. Cell Rep 2013, 5, 1159-68.

Hristov, M., W. Erl, S. Linder \& P. C. Weber: Apoptotic bodies from endothelial cells enhance the number and initiate the differentiation of human endothelial progenitor cells in vitro. Blood 2004, 104, 2761-6.

Huber, L. A. \& D. Teis: Lysosomal signaling in control of degradation pathways. Curr Opin Cell Biol 2016, 39, 8-14.

Huebner, A. R., P. Somparn, T. Benjachat, A. Leelahavanichkul, Y. Avihingsanon, R. A. Fenton \& T. Pisitkun: Exosomes in urine biomarker discovery. Adv Exp Med Biol 2015, 845, 43-58.

Hulsmans, M. \& P. Holvoet: MicroRNA-containing microvesicles regulating inflammation in association with atherosclerotic disease. Cardiovasc Res 2013, 100, 7-18.

Hung, M. E. \& J. N. Leonard: Stabilization of exosome-targeting peptides via engineered glycosylation. J Biol Chem 2015, 290, 8166-72.

Hurley, J. H.: The ESCRT complexes. Crit Rev Biochem Mol Biol 2010, 45, 463-87.

Janowska-Wieczorek, A., M. Wysoczynski, J. Kijowski, L. Marquez-Curtis, B. Machalinski, J. Ratajczak \& M. Z. Ratajczak: Microvesicles derived from activated platelets induce metastasis and angiogenesis in lung cancer. Int J Cancer 2005, 113, 752-60. 
Ji, R., B. Zhang, X. Zhang, J. Xue, X. Yuan, Y. Yan, M. Wang, W. Zhu, H. Qian \& Xu W: Exosomes derived from human mesenchymal stem cells confer drug resistance in gastric cancer. Cell Cycle 2015, 14, 2473-83.

Johansson, S. M., C. Admyre, A. Scheynius \& S. Gabrielsson: Different types of in vitro generated human monocyte-derived dendritic cells release exosomes with distinct phenotypes. Immunology 2008, 123, 491-9.

Johnstone, R. M., M. Adam, J. R. Hammond, L. Orr \& C. Turbide: Vesicle formation during reticulocyte maturation. Association of plasma membrane activities with released vesicles (exosomes). $J$ Biol Chem 1987, 262, 9412-20.

Kalra, H., R. J. Simpson, H. Ji, E. Aikawa, P. Altevogt, P. Askenase, V. C. Bond, F. E. Borras, X. Breakefield, V. Budnik, E. Buzas, G. Camussi, A. Clayton, E. Cocucci, J. M. Falcon-Perez, S. Gabrielsson, Y. S. Gho, D. Gupta, H. C. Harsha, A. Hendrix, A. F. Hill, J. M. Inal, G. Jenster, E. M. Kramer-Albers, S. K. Lim, A. Llorente, J. Lotvall, A. Marcilla, L. Mincheva-Nilsson, I. Nazarenko, R. Nieuwland, E. N. Nolte-'t Hoen, A. Pandey, T. Patel, M. G. Piper, S. Pluchino, T. S. Prasad, L. Rajendran, G. Raposo, M. Record, G. E. Reid, F. Sanchez-Madrid, R. M. Schiffelers, P. Siljander, A. Stensballe, W. Stoorvogel, D. Taylor, C. Thery, H. Valadi, B. W. van Balkom, J. Vazquez, M. Vidal, M. H. Wauben, M. Yanez-Mo, M. Zoeller \& S. Mathivanan: Vesiclepedia: a compendium for extracellular vesicles with continuous community annotation. PLoS Biol 2012, 10, e1001450.

Kanada, M., M. H. Bachmann, J. W. Hardy, D. O. Frimannson, L. Bronsart, A. Wang, M. D. Sylvester, T. L. Schmidt, R. L. Kaspar, M. J. Butte, A. C. Matin \& C. H. Contag: Differential fates of biomolecules delivered to target cells via extracellular vesicles. Proc Natl Acad Sci U S A 2015, 112, E1433-42.

Katzmann, D.J., G. Odorizzi \& S. D. Emr: Receptor downregulation and multivesicular-body sorting. Nat Rev Mol Cell Biol 2002, 3, 893-905.

Katzmann, D. J., C. J. Stefan, M. Babst \& S. D. Emr: Vps27 recruits ESCRT machinery to endosomes during MVB sorting. J Cell Biol 2003, 162, 413-23.

Kawikova, I. \& P. W. Askenase: Diagnostic and therapeutic potentials of exosomes in CNS diseases. Brain Res 2015, 1617, 63-71.

Keerthikumar, S., D. Chisanga, D. Ariyaratne, H. Al Saffar, S. Anand, K. Zhao, M. Samuel, M. Pathan, M. Jois, N. Chilamkurti, L. Gangoda \& S. Mathivanan: ExoCarta: A web-based compendium of exosomal cargo. J Mol Biol 2016, 428, 688-92.

Kim, S. H., E. R. Lechman, N. Bianco, R. Menon, A. Keravala, J. Nash, Z. Mi, S. C. Watkins, A. Gambotto \& P. D. Robbins: Exosomes derived from IL-10-treated dendritic cells can suppress inflammation and collagen-induced arthritis. J Immunol 2005, 174, 6440-8.

Kooijmans, S. A., C. G. Aleza, S. R. Roffler, W. W. van Solinge, P. Vader \& R. M. Schiffelers RM: Display of GPI-anchored anti-EGFR nanobodies on extracellular vesicles promotes tumour cell targeting. $J$ Extracell Vesicles 2016, 5, 31053.

Kooijmans, S. A., S. Stremersch, K. Braeckmans, S. C. de Smedt, A. Hendrix, M. J. Wood, R. M. Schiffelers, K. Raemdonck \& P. Vader: Electroporation-induced siRNA precipitation obscures the efficiency of siRNA loading into extracellular vesicles. J Control Release 2013, 172, 229-38.

Kooijmans, S. A., P. Vader, S. M. van Dommelen, W. W. van Solinge \& R. M. Schiffelers: Exosome mimetics: a novel class of drug delivery systems. Int J Nanomedicine 2012, 7, 1525-41.

Koppers-Lalic, D., M. Hackenberg, I. V. Bijnsdorp, M. A. van Eijndhoven, P. Sadek, D. Sie, N. Zini, J. M. Middeldorp, B. Ylstra, R. X. de Menezes, T. Wurdinger, G. A. Meijer \& D. M. Pegtel: Nontemplated nucleotide additions distinguish the small RNA composition in cells from exosomes. Cell Rep 2014, 8, 1649-58.

Kordelas, L., V. Rebmann, A. K. Ludwig, S. Radtke, J. Ruesing, T. R. Doeppner, M. Epple, P. A. Horn, D. W. Beelen \& B. Giebel: MSC-derived exosomes: a novel tool to treat therapy-refractory graft-versushost disease. Leukemia 2014, 28, 970-3.

Kosaka, N., H. Iguchi, Y. Yoshioka, F. Takeshita, Y. Matsuki \& T. Ochiya: Secretory mechanisms and intercellular transfer of microRNAs in living cells. J Biol Chem 2010, 285, 17442-52.

Kowal, J., G. Arras, M. Colombo, M. Jouve, J. P. Morath, B. Primdal-Bengtson, F. Dingli, D. Loew, M. Tkach \& C. Théry: Proteomic comparison defines novel markers to characterize heterogeneous populations of extracellular vesicle subtypes. Proc Natl Acad Sci U S A 2016, 112, E968-E977.

Kowal, J., M. Tkach \& C. Théry: Biogenesis and secretion of exosomes. Curr Opin Cell Biol 2014, 29, 11625.

Kumar, D., D. Gupta, S. Shankar \& R. K. Srivastava: Biomolecular characterization of exosomes released from cancer stem cells: Possible implications for biomarker and treatment of cancer. Oncotarget 2015, 6, 3280-91.

Lai, C. P., E. Y. Kim, C. E. Badr, R. Weissleder, T. R. Mempel, B. A. Tannous \& X. O. Breakefield: Visualization and tracking of tumour extracellular vesicle delivery and RNA translation using multiplexed reporters. Nat Commun 2015, 6, 7029. 
Lai, C. P., O. Mardini, M. Ericsson, S. Prabhakar, C. A. Maguire, J. W. Chen, B. A. Tannous \& X. O. Breakefield: Dynamic biodistribution of extracellular vesicles in vivo using a multimodal imaging reporter. ACS Nano 2014, 8, 483-94.

Lai, R. C., F. Arslan, M. M. Lee, N. S. Sze, A. Choo, T. S. Chen, M. Salto-Tellez, L. Timmers, C. N. Lee, R. M. El Oakley, G. Pasterkamp, D. P. de Kleijn \& S. K. Lim: Exosome secreted by MSC reduces myocardial ischemia/reperfusion injury. Stem Cell Res 2010, 4, 214-22.

Lakhal, S. \& M. J. Wood: Exosome nanotechnology: an emerging paradigm shift in drug delivery: exploitation of exosome nanovesicles for systemic in vivo delivery of RNAi heralds new horizons for drug delivery across biological barriers. Bioessays 2011, 33, 737-41.

Laulagnier, K., C. Motta, S. Hamdi, S. Roy, F. Fauvelle, J. F. Pageaux, T. Kobayashi, J. P. Salles, B. Perret, C. Bonnerot \& M. Record: Mast cell- and dendritic cell-derived exosomes display a specific lipid composition and an unusual membrane organization. Biochem J 2004, 380, 161-71.

Lee, C., S. A. Mitsialis, M. Aslam, S. H. Vitali, E. Vergadi, G. Konstantinou, K. Sdrimas, A. FernandezGonzalez \& S. Kourembanas: Exosomes mediate the cytoprotective action of mesenchymal stromal cells on hypoxia-induced pulmonary hypertension. Circulation 2012, 126, 2601-11.

Lee, J. K., S. R. Park, B. K. Jung, Y. K. Jeon, Y. S. Lee, M. K. Kim, Y. G. Kim, J. Y. Jang \& C. W. Kim: Exosomes derived from mesenchymal stem cells suppress angiogenesis by down-regulating VEGF expression in breast cancer cells. PLoS One 2013, 8, e84256.

Lee, K. J., J. H. Lee, H. K Chung, J. Choi, J. Park, S. S. Park, E. J. Ju, S. H. Shin, H. J. Park, E. J. Ko, N. Suh, I. Kim, J. J. Hwang, S. Y. Song, S. Y. Jeong \& E. K. Choi: Novel peptides functionally targeting in vivo human lung cancer discovered by in vivo peptide displayed phage screening. Amino Acids $2015,47,281-9$.

Levanen, B., N. R. Bhakta, P. Torregrosa Paredes, R. Barbeau, S. Hiltbrunner, J. L. Pollack, C. M. Skold, M. Svartengren, J. Grunewald, S. Gabrielsson, A. Eklund, B. M. Larsson, P. G. Woodruff, D. J. Erle \& A. M. Wheelock: Altered microRNA profiles in bronchoalveolar lavage fluid exosomes in asthmatic patients. J Allergy Clin Immunol 2013, 131, 894-903.

Li, J., K. Liu, Y. Liu, Y. Xu, F. Zhang, H. Yang, J. Liu, T. Pan, J. Chen, M. Wu, X. Zhou \& Z. Yuan: Exosomes mediate the cell-to-cell transmission of IFN-alpha-induced antiviral activity. Nat Immunol 2013a, 14, 793-803.

Li, T., Y. Yan, B. Wang, H. Qian, X. Zhang, L. Shen, M. Wang, Y. Zhou, W. Zhu, W. Li \& W. Xu: Exosomes derived from human umbilical cord mesenchymal stem cells alleviate liver fibrosis. Stem Cells Dev 2013b, 22, 845-54.

Li, Z., R. Zhao, X. Wu, Y. Sun, M. Yao, J. Li, Y. Xu \& J. Gu: Identification and characterization of a novel peptide ligand of epidermal growth factor receptor for targeted delivery of therapeutics. FASEB $J$ 2005, 19, 1978-85.

Liu, Q., D. M. Rojas-Canales, S. J. Divito, W. J. Shufesky, D. B. Stolz, G. Erdos, M. L. Sullivan, G. A. Gibson, S. C. Watkins, A. T. Larregina \& A. E. Morelli: Donor dendritic cell-derived exosomes promote allograft-targeting immune response. J Clin Invest 2016, 126, 2805-20.

Llorente, A., T. Skotland, T. Sylvanne, D. Kauhanen, T. Rog, A. Orlowski, I. Vattulainen, K. Ekroos \& K. Sandvig: Molecular lipidomics of exosomes released by PC-3 prostate cancer cells. Biochim Biophys Acta 2013, 1831, 1302-9.

Lopes-Rodrigues, V., A. Di Luca, D. Sousa, H. Seca, P. Meleady, M. Henry, R. T. Lima, R. O'Connor \& M. H. Vasconcelos: Multidrug resistant tumour cells shed more microvesicle-like EVs and less exosomes than their drug-sensitive counterpart cells. Biochim Biophys Acta 2016, 1860, 618-27.

Lynch, S., S. G. Santos, E. C. Campbell, A. M. Nimmo, C. Botting, A. Prescott, A. N. Antoniou \& S. J. Powis: Novel MHC class I structures on exosomes. J Immunol 2009, 183, 1884-91.

Maguire, C. A., L. Balaj, S. Sivaraman, M. H. Crommentuijn, M. Ericsson, L. Mincheva-Nilsson, V. Baranov, D. Gianni, B. A. Tannous, M. Sena-Esteves, X. O. Breakefield \& J. Skog: Microvesicle-associated AAV vector as a novel gene delivery system. Mol Ther 2012, 20, 960-71.

Makhadiyeva, D., L. Lam, M. Moatari, J. Vallance, Y. Zheng, E. C. Campbell \& S. J. Powis: MHC class I dimer formation by alteration of the cellular redox environment and induction of apoptosis. Immunology 2012,135, 133-9.

Malam, Y., M. Loizidou \& A. M. Seifalian AM: Liposomes and nanoparticles: nanosized vehicles for drug delivery in cancer. Trends Pharmacol Sci 2009, 30, 592-9.

Marcus, M. E. \& J. N. Leonard: FedExosomes: Engineering Therapeutic Biological Nanoparticles that Truly Deliver. Pharmaceuticals (Basel) 2013, 6, 659-80.

Martinez, M. C. \& R. Andriantsitohaina: Microparticles in angiogenesis: therapeutic potential. Circ Res 2011, 109, 110-9.

Masciopinto, F., C. Giovani, S. Campagnoli, L. Galli-Stampino, P. Colombatto, M. Brunetto, T. S. Yen, M. Houghton, P. Pileri \& S. Abrignani: Association of hepatitis $C$ virus envelope proteins with exosomes. Eur J Immunol 2004, 34, 2834-42. 
Masyuk, A. I., T. V. Masyuk \& N. F. Larusso: Exosomes in the pathogenesis, diagnostics and therapeutics of liver diseases. $J$ Hepatol 2013, 59, 621-5.

Matsumoto, S., Y. Sakata, S. Suna, D. Nakatani, M. Usami, M. Hara, T. Kitamura, T. Hamasaki, S. Nanto, Y. Kawahara \& I. Komuro: Circulating p53-responsive microRNAs are predictive indicators of heart failure after acute myocardial infarction. Circ Res 2013, 113, 322-6.

McLauchlan, J., C. Addison, M. C. Craigie \& F. J. Rixon: Noninfectious L-particles supply functions which can facilitate infection by HSV-1. Virology 1992, 190, 682-8.

Meckes, D. G., Jr. \& N. Raab-Traub: Microvesicles and viral infection. J Virol 2011, 85, 12844-54.

Meckes, D. G., Jr., K. H. Shair, A. R. Marquitz, C. P. Kung, R. H. Edwards \& N. Raab-Traub: Human tumor virus utilizes exosomes for intercellular communication. Proc Natl Acad Sci U S A 2010, 107, 203705.

Melo, S. A., L. B. Luecke, C. Kahlert, A. F. Fernandez, S. T. Gammon, J. Kaye, V. S. LeBleu, E. A. Mittendorf, J. Weitz, N. Rahbari, C. Reissfelder, C. Pilarsky, M. F. Fraga, D. Piwnica-Worms \& R. Kalluri: Glypican-1 identifies cancer exosomes and detects early pancreatic cancer. Nature 2015, 523, 177-82.

Mfunyi, C. M., M. Vaillancourt, J. Vitry, T. R. Nsimba Batomene, A. Posvandzic, A. A. Lambert \& C. Gilbert: Exosome release following activation of the dendritic cell immunoreceptor: A potential role in HIV-1 pathogenesis. Virology 2015, 484, 103-12.

Miao, Y., G. Li, X. Zhang, H. Xu \& S. N. Abraham: A TRP Channel Senses Lysosome Neutralization by Pathogens to Trigger Their Expulsion. Cell 2015, 161, 1306-19.

Mirotsou M, B. A., Tremmel I et al.: Repeated doses of cardiosphere-derived cell extracellular vesicles are hypo-immunogenic. Ed.: T. I. e. a. Blusztanj A. Journal of Extracellular Vesicles, Proceedings of the Abstracts from the 4th International Meeting of ISEV (ISEV '15), 2015.

Mishra, P. J.: Non-coding RNAs as clinical biomarkers for cancer diagnosis and prognosis. Expert Rev Mol Diagn 2014, 14, 917-9.

Mittelbrunn, M., C. Gutierrez-Vazquez, C. Villarroya-Beltri, S. Gonzalez, F. Sanchez-Cabo, M. A. Gonzalez, A. Bernad \& F. Sanchez-Madrid: Unidirectional transfer of microRNA-loaded exosomes from T cells to antigen-presenting cells. Nat Commun 2011, 2, 282.

Mittelbrunn, M. \& F. Sánchez-Madrid F: Intercellular communication: diverse structures for exchange of genetic information. Nat Rev Mol Cell Biol 2010, 13, 328-35.

Miyado, K., G. Yamada, S. Yamada, H. Hasuwa, Y. Nakamura, F. Ryu, K. Suzuki, K. Kosai, K. Inoue, A. Ogura, M. Okabe \& E. Mekada: Requirement of CD9 on the egg plasma membrane for fertilization. Science 2000, 287, 321-4.

Mizrak, A., M. F. Bolukbasi, G. B. Ozdener, G. J. Brenner, S. Madlener, E. P. Erkan, T. Strobel, X. O. Breakefield \& O. Saydam: Genetically engineered microvesicles carrying suicide mRNA/protein inhibit schwannoma tumor growth. Mol Ther 2013, 21, 101-8.

Möbius, W., Y. Ohno-Iwashita, E. G. van Donselaar, V. M. Oorschot, Y. Shimada, T. Fujimoto, H. F. Heijnen, H. J. Geuze \& J. W. Slot: Immunoelectron microscopic localization of cholesterol using biotinylated and non-cytolytic perfringolysin O. J Histochem Cytochem 2002, 50, 43-55.

Monleon, I., M. J. Martinez-Lorenzo, L. Monteagudo, P. Lasierra, M. Taules, M. Iturralde, A. Pineiro, L. Larrad, M. A. Alava, J. Naval \& A. Anel: Differential secretion of Fas ligand- or APO2 ligand/TNFrelated apoptosis-inducing ligand-carrying microvesicles during activation-induced death of human $T$ cells. J Immunol 2001, 167, 6736-44.

Montecalvo, A., A. T. Larregina, W. J. Shufesky, D. B. Stolz, M. L. Sullivan, J. M. Karlsson, C. J. Baty, G. A. Gibson, G. Erdos, Z. Wang, J. Milosevic, O. A. Tkacheva, S. J. Divito, R. Jordan, J. Lyons-Weiler, S. C. Watkins \& A. E. Morelli: Mechanism of transfer of functional microRNAs between mouse dendritic cells via exosomes. Blood 2012, 119, 756-66.

Morelli, A. E., A. T. Larregina, W. J. Shufesky, M. L. Sullivan, D. B. Stolz, G. D. Papworth, A. F. Zahorchak, A. J. Logar, Z. Wang, S. C. Watkins, L. D. Falo, Jr. \& A. W. Thomson: Endocytosis, intracellular sorting, and processing of exosomes by dendritic cells. Blood 2004, 104, 3257-66.

Morse, M. A., J. Garst, T. Osada, S. Khan, A. Hobeika, T. M. Clay, N. Valente, R. Shreeniwas, M. A. Sutton, A. Delcayre, D. H. Hsu, J. B. Le Pecq \& H. K. Lyerly: A phase I study of dexosome immunotherapy in patients with advanced non-small cell lung cancer. J Transl Med 2005, 3, 9.

Muralidharan-Chari, V., J. W. Clancy, A. Sedgwick \& C. D'Souza-Schorey: Microvesicles: mediators of extracellular communication during cancer progression. J Cell Sci 2010, 123, 1603-11.

Miyanishi, M., K. Tada, M. Koike, Y. Uchiyama, T. Kitamura \& S. Nagata: Identification of Tim4 as a phosphatidylserine receptor. Nature 2007, 450, 435-9.

Nakayama, M. Antigen presentation by MHC-dressed cells: Front Immunol 2015, 5, 672.

Noerholm, M., L. Balaj, T. Limperg, A. Salehi, L. D. Zhu, F. H. Hochberg, X. O. Breakefield, B. S. Carter \& J. Skog: RNA expression patterns in serum microvesicles from patients with glioblastoma multiforme and controls. BMC Cancer 2012, 12, 22. 
Nolte-'t Hoen, E. N., S. I. Buschow, S. M. Anderton, W. Stoorvogel \& M. H. Wauben: Activated T cells recruit exosomes secreted by dendritic cells via LFA-1. Blood 2009, 113, 1977-81.

Ohno, S., A. Ishikawa \& M. Kuroda: Roles of exosomes and microvesicles in disease pathogenesis. Adv Drug Deliv Rev 2013a, 65, 398-401.

Ohno, S., M. Takanashi, K. Sudo, S. Ueda, A. Ishikawa, N. Matsuyama, K. Fujita, T. Mizutani, T. Ohgi, T. Ochiya, N. Gotoh \& M. Kuroda: Systemically injected exosomes targeted to EGFR deliver antitumor microRNA to breast cancer cells. Mol Ther 2013b, 21, 185-91.

Okoye, I. S., S. M. Coomes, V. S. Pelly, S. Czieso, V. Papayannopoulos, T. Tolmachova, M. C. Seabra \& M. S. Wilson: MicroRNA-containing T-regulatory-cell-derived exosomes suppress pathogenic T helper 1 cells. Immunity 2014, 41, 89-103.

Pan, B. T. \& R. M. Johnstone: Fate of the transferrin receptor during maturation of sheep reticulocytes in vitro: selective externalization of the receptor. Cell 1983, 33, 967-78.

Pang, H. B., G. B. Braun, Z. G. She, V. R. Kotamraju, K. N. Sugahara, T. Teesalu \& E. Ruoslahti: A free cysteine prolongs the half-life of a homing peptide and improves its tumor-penetrating activity. $J$ Control Release 2014, 175, 48-53.

Pant, S., H. Hilton \& M. E. Burczynski: The multifaceted exosome: biogenesis, role in normal and aberrant cellular function, and frontiers for pharmacological and biomarker opportunities. Biochem Pharmacol 2012, 83, 1484-94.

Pasquetto, M. V., L. Vecchia, D. Covini, R. Digilio \& C. Scotti: Targeted drug delivery using immunoconjugates: principles and applications. J Immunother 2011, 34, 611-28.

Peche, H., B. van Denderen, J. C. Roussel, B. Trinite, J. P. Soulillou \& M. C. Cuturi: Presentation of donor major histocompatibility complex class II antigens by dna vaccination prolongs heart allograft survival. Transplantation 2004, 77, 733-40.

Pegtel, D. M., K. Cosmopoulos, D. A. Thorley-Lawson, M. A. van Eijndhoven, E. S. Hopmans, J. L. Lindenberg, T. D. de Gruijl, T. Wurdinger \& J. M. Middeldorp: Functional delivery of viral miRNAs via exosomes. Proc Natl Acad Sci U S A 2010, 107, 6328-33.

Peinado, H., M. Aleckovic, S. Lavotshkin, I. Matei, B. Costa-Silva, G. Moreno-Bueno, M. Hergueta-Redondo, C. Williams, G. Garcia-Santos, C. Ghajar, A. Nitadori-Hoshino, C. Hoffman, K. Badal, B. A. Garcia, M. K. Callahan, J. Yuan, V. R. Martins, J. Skog, R. N. Kaplan, M. S. Brady, J. D. Wolchok, P. B. Chapman, Y. Kang, J. Bromberg \& D. Lyden: Melanoma exosomes educate bone marrow progenitor cells toward a pro-metastatic phenotype through MET. Nat Med 2012, 18, 883-91.

Perez-Gonzalez, R., S. A. Gauthier, A. Kumar \& E. Levy: The exosome secretory pathway transports amyloid precursor protein carboxyl-terminal fragments from the cell into the brain extracellular space. J Biol Chem 2012, 287, 43108-15.

Pfeffer, S. R.: Two Rabs for exosome release. Nat Cell Biol 2010, 12, 3-4.

Pitt, J. M., F. André, S. Amigorena, J. C. Soria, A. Eggermont, G. Kroemer \& L. Zitvogel: Dendritic cellderived exosomes for cancer therapy. J Clin Invest 2016, 126, 1224-32.

Prada, I. \& J. Meldolesi: Binding and fusion of extracellular vesicles to the plasma membrane of their cell targets. Int J Mol Sci 2016, 9, 17.

Puryear, W. B., X. Yu, N. P. Ramirez, B. M. Reinhard \& S. Gummuluru: HIV-1 incorporation of host-cellderived glycosphingolipid GM3 allows for capture by mature dendritic cells. Proc Natl Acad Sci USA 2012, 109, 7475-80.

Pusic, A. D. \& R. P. Kraig: Youth and environmental enrichment generate serum exosomes containing miR219 that promote CNS myelination. Glia 2014, 62, 284-99.

Qu, J. L., X. J. Qu, M. F. Zhao, Y. E. Teng, Y. Zhang, K. Z. Hou, Y. H. Jiang, X. H. Yang \& Y. P. Liu: Gastric cancer exosomes promote tumour cell proliferation through PI3K/Akt and MAPK/ERK activation. Dig Liver Dis 2009, 41, 875-80.

Quesenberry, P. J., L. R. Goldberg, J. M. Aliotta, M. S. Dooner, M. G. Pereira, S. Wen \& G. Camussi: Cellular phenotype and extracellular vesicles: Basic and clinical considerations. Stem Cells Dev 2014, 23, 1429-36.

Rahman, M. J., D. Regn, R. Bashratyan \& Y. D. Dai: Exosomes released by islet-derived mesenchymal stem cells trigger autoimmune responses in NOD mice. Diabetes 2014, 63, 1008-20.

Raiborg, C. \& H. Stenmark: The ESCRT machinery in endosomal sorting of ubiquitylated membrane proteins. Nature 2009, 458, 445-52.

Rajendran, L., J. Bali, M. M. Barr, F. A. Court, E. M. Kramer-Albers, F. Picou, G. Raposo, K. E. van der Vos, G. van Niel, J. Wang \& X. O. Breakefield: Emerging roles of extracellular vesicles in the nervous system. J Neurosci 2014, 34, 15482-9.

Rajendran, L., M. Honsho, T. R. Zahn, P. Keller, K. D. Geiger, P. Verkade \& K. Simons: Alzheimer's disease beta-amyloid peptides are released in association with exosomes. Proc Natl Acad Sci U S A 2006, 103, 11172-7. 
Rana, S. \& M. Zoller: Exosome target cell selection and the importance of exosomal tetraspanins: a hypothesis. Biochem Soc Trans 2011, 39, 559-62.

Ranghino, A., V. Cantaluppi, C. Grange, L. Vitillo, F. Fop, L. Biancone, M. C. Deregibus, C. Tetta, G. P. Segoloni \& G. Camussi: Endothelial progenitor cell-derived microvesicles improve neovascularization in a murine model of hindlimb ischemia. Int $J$ Immunopathol Pharmacol 2012, 25, 75-85.

Ratajczak, J., M. Wysoczynski, F. Hayek, A. Janowska-Wieczorek \& M. Z. Ratajczak: Membrane-derived microvesicles: important and underappreciated mediators of cell-to-cell communication. Leukemia 2006, 20, 1487-95.

Rechavi, O., Y. Erlich, H. Amram, L. Flomenblit, F. V. Karginov, I. Goldstein, G. J. Hannon \& Y. Kloog: Cell contact-dependent acquisition of cellular and viral nonautonomously encoded small RNAs. Genes Dev 2009, 23, 1971-9.

Record, M., C. Subra, S. Silvente-Poirot \& M. Poirot: Exosomes as intercellular signalosomes and pharmacological effectors. Biochem Pharmacol 2011, 81, 1171-82.

Revenfeld, A. L., R. Baek, M. H. Nielsen, A. Stensballe, K. Varming \& M. Jorgensen: Diagnostic and prognostic potential of extracellular vesicles in peripheral blood. Clin Ther 2014, 36, 830-46.

Robbins, P. D. \& A. E. Morelli: Regulation of immune responses by extracellular vesicles. Nat Rev Immunol 2014, 14, 195-208.

Rossman, J. S. \& R. A. Lamb: Influenza virus assembly and budding. Virology 2011, 411, 229-36.

Roucourt, B., S. Meeussen, J. Bao, P. Zimmermann \& G. David: Heparanase activates the syndecansyntenin-ALIX exosome pathway. Cell Res 2015, 25, 412-28.

Rountree, R. B., S. J. Mandl, J. M. Nachtwey, K. Dalpozzo, L. Do, J. R. Lombardo, P. L. Schoonmaker, K. Brinkmann, U. Dirmeier, R. Laus \& A. Delcayre: Exosome targeting of tumor antigens expressed by cancer vaccines can improve antigen immunogenicity and therapeutic efficacy. Cancer Res 2011, 71, 5235-44.

Ruiss, R., S. Jochum, R. Mocikat, W. Hammerschmidt \& R. Zeidler R: EBV-gp350 confers B-cell tropism to tailored exosomes is a neo-antigen in normal and malignant $B$ cells: a new option for the treatment of B-CLL. PLoS One 2011, 6, e25294.

Saa, P., O. Yakovleva, J. de Castro, I. Vasilyeva, S. H. De Paoli, J. Simak \& L. Cervenakova: First demonstration of transmissible spongiform encephalopathy-associated prion protein (PrPTSE) in extracellular vesicles from plasma of mice infected with mouse-adapted variant Creutzfeldt-Jakob disease by in vitro amplification. J Biol Chem 2014, 289, 29247-60.

Saman, S., W. Kim, M. Raya, Y. Visnick, S. Miro, B. Jackson, A. C. McKee, V. E. Alvarez, N. C. Lee \& G. F. Hall: Exosome-associated tau is secreted in tauopathy models and is selectively phosphorylated in cerebrospinal fluid in early Alzheimer disease. J Biol Chem 2012, 287, 3842-9.

Sandbu, S., B. Feiring, P. Oster, O. S. Helland, H. S. Bakke, L. M. Naess, A. Aase, I. S. Aaberge, A. C. Kristoffersen, K. M. Rydland, S. Tilman, H. Nokleby \& E. Rosenqvist: Immunogenicity and safety of a combination of two serogroup B meningococcal outer membrane vesicle vaccines. Clin Vaccine Immunol 2007, 14, 1062-9.

Saunderson, S. C., A. C. Dunn, P. R. Crocker \& A. D. McLellan: CD169 mediates the capture of exosomes in spleen and lymph node. Blood 2014, 123, 208-16.

Schwarzenbach, H.: The clinical relevance of circulating, exosomal miRNAs as biomarkers for cancer. Expert Rev Mol Diagn 2015, 15, 1159-69.

Sedlik, C., J. Vigneron, L. Torrieri-Dramard, F. Pitoiset, J. Denizeau, C. Chesneau, P. de la Rochere, O. Lantz, C. Thery \& B. Bellier: Different immunogenicity but similar antitumor efficacy of two DNA vaccines coding for an antigen secreted in different membrane vesicle-associated forms. $J$ Extracell Vesicles 2014, 3 (http://dx.doi.org/10.3402/jev.v3.24646).

Segura, E., S. Amigorena \& C. Thery: Mature dendritic cells secrete exosomes with strong ability to induce antigen-specific effector immune responses. Blood Cells Mol Dis 2005, 35, 89-93.

Seow, Y. \& M. J. Wood: Biological gene delivery vehicles: beyond viral vectors. Mol Ther 2009, 17, 767-77.

Shantsila, E., P. W. Kamphuisen \& G. Y. Lip: Circulating microparticles in cardiovascular disease: implications for atherogenesis and atherothrombosis. J Thromb Haemost 2010, 8, 2358-68.

Shavnin, S. A., M. C. Pedroso de Lima, J. Fedor, P. Wood, J. Bentz \& N. Duzgunes: Cholesterol affects divalent cation-induced fusion and isothermal phase transitions of phospholipid membranes. Biochim Biophys Acta 1988, 946, 405-16.

Shedden, K., X. T. Xie, P. Chandaroy, Y. T. Chang \& G. R. Rosania: Expulsion of small molecules in vesicles shed by cancer cells: association with gene expression and chemosensitivity profiles. Cancer Res 2003, 63, 4331-7.

Shen, B., N. Wu, J. M. Yang \& S. J. Gould: Protein targeting to exosomes/microvesicles by plasma membrane anchors. J Biol Chem 2011, 286, 14383-95. 
Simons, M. \& G. Raposo: Exosomes--vesicular carriers for intercellular communication. Curr Opin Cell Biol 2009, 21, 575-81.

Simpson, R. J., J. W. Lim, R. L. Moritz \& S. Mathivanan: Exosomes: proteomic insights and diagnostic potential. Expert Rev Proteomics 2009, 6, 267-83.

Skog, J., T. Wurdinger, S. van Rijn, D. H. Meijer, L. Gainche, M. Sena-Esteves, W. T. Curry, Jr., B. S. Carter, A. M. Krichevsky \& X. O. Breakefield: Glioblastoma microvesicles transport RNA and proteins that promote tumour growth and provide diagnostic biomarkers. Nat Cell Biol 2008, 10, 1470-6.

Skokos, D., H. Goubran-Botros, M. Roa \& S. Mecheri: Immunoregulatory properties of mast cell-derived exosomes. Mol Immunol 2002, 38, 1359-62.

Smith, G.P.: Filamentous fusion phage: novel expression vectors that display cloned antigens on the virion surface. Science 1985, 228, 1315-7.

Smyth, T., M. Kullberg, N. Malik, P. Smith-Jones, M. W. Graner \& T. J. Anchordoquy: Biodistribution and delivery efficiency of unmodified tumor-derived exosomes. J. Control. Release 2015, 199, 145-55.

Spanu, S., C. R. van Roeyen, B. Denecke, J. Floege \& A. S. Muhlfeld: Urinary exosomes: a novel means to non-invasively assess changes in renal gene and protein expression. PLoS One 2014, 9, e109631.

Squadrito, M. L., C. Baer, F. Burdet, C. Maderna, G. D. Gilfillan, R. Lyle, M. Ibberson \& M. De Palma: Endogenous RNAs modulate microRNA sorting to exosomes and transfer to acceptor cells. Cell Rep 2014, 8, 1432-46.

Stenmark, H.: Rab GTPases as coordinators of vesicle traffic. Nat Rev Mol Cell Biol 2009, 10, 513-25.

Stenqvist, A. C., O. Nagaeva, V. Baranov \& L. Mincheva-Nilsson: Exosomes secreted by human placenta carry functional Fas ligand and TRAIL molecules and convey apoptosis in activated immune cells, suggesting exosome-mediated immune privilege of the fetus. J Immunol 2013, 191, 5515-23.

Stoorvogel, W.: Resolving sorting mechanisms into exosomes. Cell Res 2015, 25, 531-2.

Sugimachi, K., T. Matsumura, H. Hirata, R. Uchi, M. Ueda, H. Ueo, Y. Shinden, T. Iguchi, H. Eguchi, K. Shirabe, T. Ochiya, Y. Maehara \& K. Mimori: Identification of a bona fide microRNA biomarker in serum exosomes that predicts hepatocellular carcinoma recurrence after liver transplantation. $\mathrm{Br} J$ Cancer 2015, 112, 532-8.

Sun, D., X. Zhuang, X. Xiang, Y. Liu, S. Zhang, C. Liu, S. Barnes, W. Grizzle, D. Miller \& H. G. Zhang: A novel nanoparticle drug delivery system: the anti-inflammatory activity of curcumin is enhanced when encapsulated in exosomes. Mol Ther 2010, 18, 1606-14.

Sung, B. H., T. Ketova, D. Hoshino, A. Zijlstra \& A. M. Weaver: Directional cell movement through tissues is controlled by exosome secretion. Nature Comm 2015, 7164, 1-14.

Takeda, Y. S. \& Q. Xu: Neuronal differentiation of human mesenchymal stem cells using exosomes rerived from differentiating neuronal cells. PLoS One 2015, 10, e0135111.

Tamai, K., N. Tanaka, T. Nakano, E. Kakazu, Y. Kondo, J. Inoue, M. Shiina, K. Fukushima, T. Hoshino, K. Sano, Y. Ueno, T. Shimosegawa \& K. Sugamura: Exosome secretion of dendritic cells is regulated by Hrs, an ESCRT-0 protein. Biochem Biophys Res Commun 2010, 399, 384-90.

Tavoosidana, G., G. Ronquist, S. Darmanis, J. Yan, L. Carlsson, D. Wu, T. Conze, P. Ek, A. Semjonow, E. Eltze, A. Larsson, U. D. Landegren \& M. Kamali-Moghaddam: Multiple recognition assay reveals prostasomes as promising plasma biomarkers for prostate cancer. Proc Natl Acad Sci U S A 2011, 108, 8809-14.

Taylor, D. D., S. Akyol \& C. Gercel-Taylor: Pregnancy-associated exosomes and their modulation of T cell signaling. J Immunol 2006, 176, 1534-42.

Taylor, D. D. \& C. Gercel-Taylor: Tumour-derived exosomes and their role in cancer-associated T-cell signalling defects. Br J Cancer 2005, 92, 305-11.

Taylor, D. D. \& C. Gercel-Taylor: MicroRNA signatures of tumor-derived exosomes as diagnostic biomarkers of ovarian cancer. Gynecol Oncol 2008, 110, 13-21.

Taylor, D. D. \& S. Shah: Methods of isolating extracellular vesicles impact down-stream analyses of their cargoes. Methods 2015.

Temchura, V. V., M. Tenbusch, G. Nchinda, G. Nabi, B. Tippler, M. Zelenyuk, O. Wildner, K. Uberla \& S. Kuate: Enhancement of immunostimulatory properties of exosomal vaccines by incorporation of fusion-competent $\mathrm{G}$ protein of vesicular stomatitis virus. Vaccine 2008, 26, 3662-72.

Thapa, N., H. Y. Hong, P. Sangeetha, I. S. Kim, J. Yoo, K. Rhee, G. T. Oh, I. C. Kwon \& B. H. Lee: Identification of a peptide ligand recognizing dysfunctional endothelial cells for targeting atherosclerosis. J Control Release 2008, 131, 27-33.

Thery, C., L. Duban, E. Segura, P. Veron, O. Lantz \& S. Amigorena: Indirect activation of naive CD4+ T cells by dendritic cell-derived exosomes. Nat Immunol 2002, 3, 1156-62.

Tian, Y., S. Li, J. Song, T. Ji, M. Zhu, G. J. Anderson, J. Wei \& G. Nie: A doxorubicin delivery platform using engineered natural membrane vesicle exosomes for targeted tumor therapy. Biomaterials 2014, 35, 2383-90. 
Tian, T., Y. Wang, H. Wang, Z. Zhu \& Z. Xiao: Visualizing of the cellular uptake and intracellular trafficking of exosomes by live-cell microscopy. J Cell Biochem 2010, 111, 488-96.

Tian, T., Y. L. Zhu, F. H. Hu, Y. Y. Wang, N. P. Huang \& Z. D. Xiao: Dynamics of exosome internalization and trafficking. J Cell Physiol 2013, 228, 1487-95.

Tomlinson, P. R., Y. Zheng, R. Fischer, R. Heidasch, C. Gardiner, S. Evetts, M. Hu, R. Wade-Martins, M. R. Turner, J. Morris, K. Talbot, B. M. Kessler \& G. K. Tofaris: Identification of distinct circulating exosomes in Parkinson's disease. Ann Clin Transl Neurol 2015, 2, 353-61.

Trajkovic, K., C. Hsu, S. Chiantia, L. Rajendran, D. Wenzel, F. Wieland, P. Schwille, B. Brügger \& M. Simons: Ceramide triggers budding of exosome vesicles into multivesicular endosomes. Science 2008, 319, 1244-47.

Trams, E. G., C. J. Lauter, N. Salem, Jr. \& U. Heine: Exfoliation of membrane ecto-enzymes in the form of micro-vesicles. Biochim Biophys Acta 1981, 645, 63-70.

Vader, P., S. A. Kooijmans, S. Stremersch \& K. Raemdonck: New considerations in the preparation of nucleic acid-loaded extracellular vesicles. Ther Deliv 2014, 5, 105-7.

Valadi, H., K. Ekstrom, A. Bossios, M. Sjostrand, J. J. Lee \& J. O. Lotvall: Exosome-mediated transfer of mRNAs and microRNAs is a novel mechanism of genetic exchange between cells. Nat Cell Biol 2007, 9, 654-9.

Vallhov, H., C. Gutzeit, S. M. Johansson, N. Nagy, M. Paul, Q. Li, S. Friend, T. C. George, E. Klein, A. Scheynius \& S. Gabrielsson S: Exosomes containing glycoprotein 350 released by EBV-transformed $B$ cells selectively target B cells through CD21 and block EBV infection in vitro. J Immunol 2011, $186,73-82$.

van den Boorn, J. G., M. Schlee, C. Coch \& G. Hartmann: SiRNA delivery with exosome nanoparticles. Nat Biotechnol 2011, 29, 325-6.

van der Meel, R., M. H. Fens, P. Vader, W. W. van Solinge, O. Eniola-Adefeso \& R. M. Schiffelers: Extracellular vesicles as drug delivery systems: lessons from the liposome field. $J$ Control Release 2014, 195, 72-85.

van der Vlist, E. J., G. J. Arkesteijn, C. H. van de Lest, W. Stoorvogel, E. N. Nolte-'t Hoen \& M. H. Wauben: CD4(+) $\mathrm{T}$ cell activation promotes the differential release of distinct populations of nanosized vesicles. J Extracell Vesicles 2012, 1

van Dongen, H. M., N. Masoumi, K. W. Witwer \& D. M. Pegtel: Extracellular vesicles exploit viral entry routes for cargo delivery. Microbiol Mol Biol Rev 2016, 80, 369-86.

van Lummel, M., W. J. van Blitterswijk, S. R. Vink, R. J. Veldman, M. A. van der Valk, D. Schipper, B. M. Dicheva, A. M. Eggermont, T. L. ten Hagen, M. Verheij \& G. A. Koning: Enriching lipid nanovesicles with short-chain glucosylceramide improves doxorubicin delivery and efficacy in solid tumors. FASEB J 2011, 25, 280-9.

van Niel, G., G. Raposo, C. Candalh, M. Boussac, R. Hershberg, N. Cerf-Bensussan \& M. Heyman: Intestinal epithelial cells secrete exosome-like vesicles. Gastroenterology 2001, 121, 337-49.

Varnier, A., F. Kermarrec, I. Blesneac, C. Moreau, L. Liguori, J. L. Lenormand \& N. Picollet-D'hahan: A simple method for the reconstitution of membrane proteins into giant unilamellar vesicles. $J$ Membr Biol 2010, 233, 85-92.

Verweij, F. J. , J. M. Middeldorp \& D. M. Pegtel: Intracellular signaling controlled by the endosomal-exosomal pathway. Commun Integr Biol 2012, 5, 88-93.

Viaud, S., C. Thery, S. Ploix, T. Tursz, V. Lapierre, O. Lantz, L. Zitvogel \& N. Chaput: Dendritic cell-derived exosomes for cancer immunotherapy: what's next? Cancer Res 2010, 70, 1281-5.

Vicencio, J. M., D. M. Yellon, V. Sivaraman, D. Das, C. Boi-Doku, S. Arjun, Y. Zheng, J. A. Riquelme, J. Kearney, V. Sharma, G. Multhoff, A. R. Hall \& S. M. Davidson: Plasma exosomes protect the myocardium from ischemia-reperfusion injury. J Am Coll Cardiol 2015, 65, 1525-36.

Villarroya-Beltri, C., F. Baixauli, C. Gutiérrez-Vázquez, F. Sánchez-Madrid \& M. Mittelbrunn: Sorting it out: regulation of exosome loading. Semin Cancer Biol 2014, 28, 3-13.

Villarroya-Beltri, C., C. Gutierrez-Vazquez, F. Sanchez-Cabo, D. Perez-Hernandez, J. Vazquez, N. MartinCofreces, D. J. Martinez-Herrera, A. Pascual-Montano, M. Mittelbrunn \& F. Sanchez-Madrid: Sumoylated hnRNPA2B1 controls the sorting of miRNAs into exosomes through binding to specific motifs. Nat Commun 2013, 4, 2980.

Wahlgren, J., T. De L. Karlson, M. Brisslert, F. Vaziri Sani, E. Telemo, P. Sunnerhagen \& H. Valadi: Plasma exosomes can deliver exogenous short interfering RNA to monocytes and lymphocytes. Nucleic Acids Res 2012, 40, e130.

Wang, H., Y. Jiang, H. Peng, Y. Chen, P. Zhu \& Y. Huang: Recent progress in microRNA delivery for cancer therapy by non-viral synthetic vectors. Adv Drug Deliv Rev 2015, 81, 142-60.

Wolfers, J., A. Lozier, G. Raposo, A. Regnault, C. Thery, C. Masurier, C. Flament, S. Pouzieux, F. Faure, T. Tursz, E. Angevin, S. Amigorena \& L. Zitvogel: Tumor-derived exosomes are a source of shared tumor rejection antigens for CTL cross-priming. Nat Med 2001, 7, 297-303. 
Xin, H., Y. Li, B. Buller, M. Katakowski, Y. Zhang, X. Wang, X. Shang, Z. G. Zhang \& M. Chopp: Exosomemediated transfer of miR-133b from multipotent mesenchymal stromal cells to neural cells contributes to neurite outgrowth. Stem Cells 2012, 30, 1556-64.

Xitong, D. \& Z. Xiaorong: Targeted therapeutic delivery using engineered exosomes and its applications in cardiovascular diseases. Gene 2016, 575, 377-84.

Xu, R., D. W. Greening, H. J. Zhu, N. Takahashi \& R. J. Simpson: Extracellular vesicle isolation and characterization: toward clinical application. J Clin Invest 2016, 126, 1152-62.

Yamashita, T., H. Kamada, S. Kanasaki, Y. Maeda, K. Nagano, Y. Abe, M. Inoue, Y. Yoshioka, Y. Tsutsumi, S. Katayama \& S. Tsunoda: Epidermal growth factor receptor localized to exosome membranes as a possible biomarker for lung cancer diagnosis. Pharmazie 2013, 68, 969-73.

Yanez-Mo, M., O. Barreiro, M. Gordon-Alonso, M. Sala-Valdes \& F. Sanchez-Madrid: Tetraspanin-enriched microdomains: a functional unit in cell plasma membranes. Trends Cell Biol 2009, 19, 434-46.

Yang, Y., A. Otte \& R. Hass: Human mesenchymal stroma/stem cells exchange membrane proteins and alter functionality during interaction with different tumor cell lines. Stem Cells Dev 2015, 24, 1205-22.

Yates, L. A., C. J. Norbury \& R. J. Gilbert: The long and short of microRNA. Cell 2013, 153, 516-9.

Yeo, R. W., R. C. Lai, B. Zhang, S. S. Tan, Y. Yin, B. J. Teh \& S. K. Lim: Mesenchymal stem cell: an efficient mass producer of exosomes for drug delivery. Adv Drug Deliv Rev 2013, 65, 336-41.

Yu, K. F., W. Q. Zhang, L. M. Luo, P. Song, D. Li, R Du, W. Ren, D. Huang, W. L. Lu, X. Zhang \& Q. Zhang: The antitumor activity of a doxorubicin loaded, iRGD-modified sterically-stabilized liposome on B16F10 melanoma cells: in vitro and in vivo evaluation. Int $J$ Nanomedicine 2013, 8, 2473-85.

Yuyama, K., H. Sun, S. Usuki, S. Sakai, H. Hanamatsu, T. Mioka, N. Kimura, M. Okada, H. Tahara, J. Furukawa, N. Fujitani, Y. Shinohara \& Y. Igarashi: A potential function for neuronal exosomes: sequestering intracerebral amyloid-beta peptide. FEBS Lett 2015, 589, 84-8.

Zeelenberg, I. S., M. Ostrowski, S. Krumeich, A. Bobrie, C. Jancic, A. Boissonnas, A. Delcayre, J. B. Le Pecq, B. Combadiere, S. Amigorena \& C. Thery: Targeting tumor antigens to secreted membrane vesicles in vivo induces efficient antitumor immune responses. Cancer Res 2008, 68, 1228-35.

Zhang, B., Y. Yin, R. C. Lai \& S. K. Lim: Immunotherapeutic potential of extracellular vesicles. Front Immunol 2014, 5, 518.

Zhang, Y., M. Chopp, Y. Meng, M. Katakowski, H. Xin, A. Mahmood \& Y. Xiong: Effect of exosomes derived from multipluripotent mesenchymal stromal cells on functional recovery and neurovascular plasticity in rats after traumatic brain injury. J Neurosurg 2015, 122, 856-67.

Zhao, L., W. Liu, J. Xiao \& B. Cao: The role of exosomes and "exosomal shuttle microRNA" in tumorigenesis and drug resistance. Cancer Lett 2015, 356, 339-46.

Zhou, H., T. Pisitkun, A. Aponte, P. S. Yuen, J. D. Hoffert, H. Yasuda, X. Hu, L. Chawla, R. F. Shen, M. A. Knepper \& R. A. Star: Exosomal Fetuin-A identified by proteomics: a novel urinary biomarker for detecting acute kidney injury. Kidney Int 2006, 70, 1847-57.

Zhou, W., M. Y. Fong, Y. Min, G. Somlo, L. Liu, M. R. Palomares, Y. Yu, A. Chow, S. T. O'Connor, A. R. Chin, Y. Yen, Y. Wang, E. G. Marcusson, P. Chu, J. Wu, X. Wu, A. X. Li, Z. Li, H. Gao, X. Ren, M. P. Boldin, P. C. Lin \& S. E. Wang: Cancer-secreted miR-105 destroys vascular endothelial barriers to promote metastasis. Cancer Cell 2014, 25, 501-15.

Zhu, C. Y., Y. Shen \& Q. Xu: Propagation of dysbindin-1B aggregates: exosome-mediated transmission of neurotoxic deposits. Neuroscience 2015, 291, 301-16.

Zhuang, X., X. Xiang, W. Grizzle, D. Sun, S. Zhang, R. C. Axtell, S. Ju, J. Mu, L. Zhang, L. Steinman, D. Miller \& H. G. Zhang: Treatment of brain inflammatory diseases by delivering exosome encapsulated anti-inflammatory drugs from the nasal region to the brain. Mol Ther 2011, 19, 1769-79.

Zhuo, Y., S. H. Li, M. S. Chen, J. Wu, H. Y. Kinkaid, S. Fazel, R. D. Weisel \& R. K. Li RK: Aging impairs the angiogenic response to ischemic injury and the activity of implanted cells: combined consequences for cell therapy in older recipients. J Thorac Cardiovasc Surg 2010, 139, 1286-94.

Zitvogel, L., A. Regnault, A. Lozier, J. Wolfers, C. Flament, D. Tenza, P. Ricciardi-Castagnoli, G. Raposo \& $\mathrm{S}$. Amigorena: Eradication of established murine tumors using a novel cell-free vaccine: dendritic cell-derived exosomes. Nat Med 1998, 4, 594-600. 


\section{Legends}

Figure 1. Biogenesis of exosomes and interactions with recipient cells. Exosomes originate by internal budding of the plasma membrane giving rise to early endosomes. By maturation through a process that involves interactions with the Golgi complex, early endosomes become late endosomes. The membrane of late endosomes forms intraluminal vesicles (ILVs) that have incorporated proteins from the plasma membrane and from the Golgi, along with nucleic acids. ILVs are contained within multivesicular bodies (MVBs) that either fuse with the plasma membrane to release them as exosomes into the extracellular space, or are sent to lysosomes for degradation. The endosomal-sorting complex required for transport (ESCRT) is the key molecular machinery of protein sorting into exosomes. TSG101 (tumour susceptibility gene 101) is a component of the ESCRT-1 sub-complex. Exosomes may interact in several ways with recipient cells, e.g., by fusion and intracellular delivery of cargo molecules, by transfer of activated receptors, and via ligand-receptor interaction.

Figure 2. Bioengineered EVs for targeted drug delivery. Examples of EV targeting to specific recipient cells are shown. Targeting may be accomplished by engineering the parent cells using fusion constructs between a targeting ligand and an EV transmembrane protein, such as LAMP-2b or PDGFR TM domain. Targeting ligands may include naturally occurring molecules, such as EBV gp350 (which selectively binds to B cells via interaction with the B lineage marker CD21), RVG (which targets nACh receptor on neurons), and sialic acid residues (which mediate uptake by macrophages through binding to CD169). ICAM-1 contributes to B-cell binding through interaction with LFA-1. Examples of synthetic targeting peptides displayed on te EV surface include GE11 (which targets EGFR on tumour cells) and iRGD (which targets integrins and neuropilins). AntiEGCF-nanobodies linked to GPI-anchors through GGGGS2 linkers have been used to target EGFR on tumour cells. VSV-G indiscriminately facilitates cell fusion. EVs may carry cargo small-molecule drugs and/or nucleic acids (Abbreviations: EBV, Epstein-Barr virus; EGFR, epidermal growth factor receptor; GPI, glycosylphosphatidylinositol; ICAM-1, intercellular adhesion molecule-1; iRGD, internalizing arginine-glycineasparagine; LAMP-2, Iysosome-associated membrane protein-2; LFA-1, lymphocyte function-associated antigen-1; nACh, nicotinic acetylcholine; PDGFR TM domain, platelet-derived growth factor receptor, transmembrane domain; RVG, rabies virus glycoprotein; VSV-G, vesicular stomatitis virus glycoprotein). 
Table 1: Ongoing clinical studies of diagnostic EV markers

\begin{tabular}{|l|l|l|l|l|l|}
\hline STUDY & STATUS & TOPIC & REGION & $\begin{array}{l}\text { SOURCE OF } \\
\text { EXOSOMES }\end{array}$ & $\begin{array}{l}\text { ClinicalTrials.gov } \\
\text { IDENTIFIER }\end{array}$ \\
\hline $\begin{array}{l}\text { Interrogation of Exosome-mediated Intercellular Signaling in } \\
\text { Patients With Pancreatic Cancer }\end{array}$ & Recruiting & Cancer & USA & Blood & NCT02393703 \\
\hline $\begin{array}{l}\text { Clinical Validation of a Urinary Exosome Gene Signature in Men } \\
\text { Presenting for Suspicion of Prostate Cancer }\end{array}$ & Completed & Cancer & USA & Urine & NCT02702856 \\
\hline $\begin{array}{l}\text { Circulating Exosomes As Potential Prognostic And Predictive } \\
\text { Biomarkers In Advanced Gastric Cancer Patients ("EXO-PPP Study") }\end{array}$ & Recruiting & Cancer & Europe & Blood & NCT01779583 \\
\hline $\begin{array}{l}\text { Exosome Testing as a Screening Modality for Human } \\
\text { Papillomavirus-Positive Oropharyngeal Squamous Cell Carcinoma }\end{array}$ & Recruiting & Cancer & USA & $\begin{array}{l}\text { Cultured Primary } \\
\text { Cells }\end{array}$ & NCT02147418 \\
\hline LRRK2 and Other Novel Exosome Proteins in Parkinson's Disease & Recruiting & Parkinson & USA & Blood, Urine & NCT01860118 \\
\hline $\begin{array}{l}\text { Pilot Study With the Aim to Quantify a Stress Protein in the Blood } \\
\text { and in the Urine for the Monitoring and Early Diagnosis of } \\
\text { Malignant Solid Tumors (EXODIAG) }\end{array}$ & Recruiting & Cancer & Europe & Blood, Urine & NCT02662621 \\
\hline $\begin{array}{l}\text { Isolation and Characterization of the Extracellular Vesicles } \\
\text { Secreted by the Human Endometrium }\end{array}$ & Recruiting & & Europe & Endometrial fluid & NCT02797834 \\
\hline $\begin{array}{l}\text { Early Biomarkers of Tumor Response in High Dose } \\
\text { Hypofractionated Radiotherapy Word Package 3: Immune } \\
\text { Response }\end{array}$ & Recruiting & Cancer & Europe & Blood & NCT02439008 \\
\hline $\begin{array}{l}\text { Evaluation of MicroRNA Expression in Blood and Cytology for } \\
\text { Detecting Barrett's Esophagus and Associated Neoplasia }\end{array}$ & Recruiting & Cancer & USA & Bile & NCT02464930 \\
\hline
\end{tabular}




\section{Table 2: Planned or ongoing therapeutic clinical studies}

\begin{tabular}{|c|c|c|c|c|c|c|c|}
\hline STUDY & STATUS & TOPIC & PHASE & REGION & $\begin{array}{l}\text { SOURCE OF } \\
\text { EXOSOMES }\end{array}$ & $\begin{array}{l}\text { ROUTE OF } \\
\text { ADMINISTRATION }\end{array}$ & $\begin{array}{l}\text { ClinicalTrials.gov } \\
\text { IDENTIFIER }\end{array}$ \\
\hline $\begin{array}{l}\text { Study Investigating the Ability of Plant Exosomes to Deliver } \\
\text { Curcumin to Normal and Colon Cancer Tissue }\end{array}$ & Unknown & Cancer & 1 & USA & $\begin{array}{l}\text { Plant Exosomes } \\
\text { (curcuma) }\end{array}$ & Dietary Supplement & NCT01294072 \\
\hline Effect of Plasma Derived Exosomes on Cutaneous Wound Healing & $\begin{array}{l}\text { Not Yet } \\
\text { Recruiting }\end{array}$ & Ulcer & & East Asia & $\begin{array}{l}\text { Autologus Blood } \\
\text { Exosomes }\end{array}$ & $\begin{array}{l}\text { Local application } \\
\text { (daily) }\end{array}$ & NCT02565264 \\
\hline $\begin{array}{l}\text { Effect of Microvesicles and Exosomes Therapy on } \beta \text {-cell Mass in } \\
\text { Type I Diabetes Mellitus (T1DM) }\end{array}$ & $\begin{array}{l}\text { Enrolling } \\
\text { by } \\
\text { invitation }\end{array}$ & Diabetes & IIIIII & Africa & $\begin{array}{l}\text { Umbilical cord- } \\
\text { blood derived MSC } \\
\text { microvesicles }\end{array}$ & Intravenous Infusion & NCT02138331 \\
\hline $\begin{array}{l}\text { Edible Plant Exosome Ability to Prevent Oral Mucositis Associated } \\
\text { With Chemoradiation Treatment of Head and Neck Cancer }\end{array}$ & Recruiting & Cancer & 1 & USA & $\begin{array}{l}\text { Plant exosomes } \\
\text { (grape) }\end{array}$ & Dietary Supplement & NCT01668849 \\
\hline $\begin{array}{l}\text { Trial of a Vaccination With Tumor Antigen-loaded Dendritic Cell- } \\
\text { derived Exosomes (CSET 1437) }\end{array}$ & Unknown & Cancer & II & Europe & $\begin{array}{l}\text { Dendritic cell- } \\
\text { derived exosomes }\end{array}$ & Vaccination (orally) & NCT01159288 \\
\hline
\end{tabular}




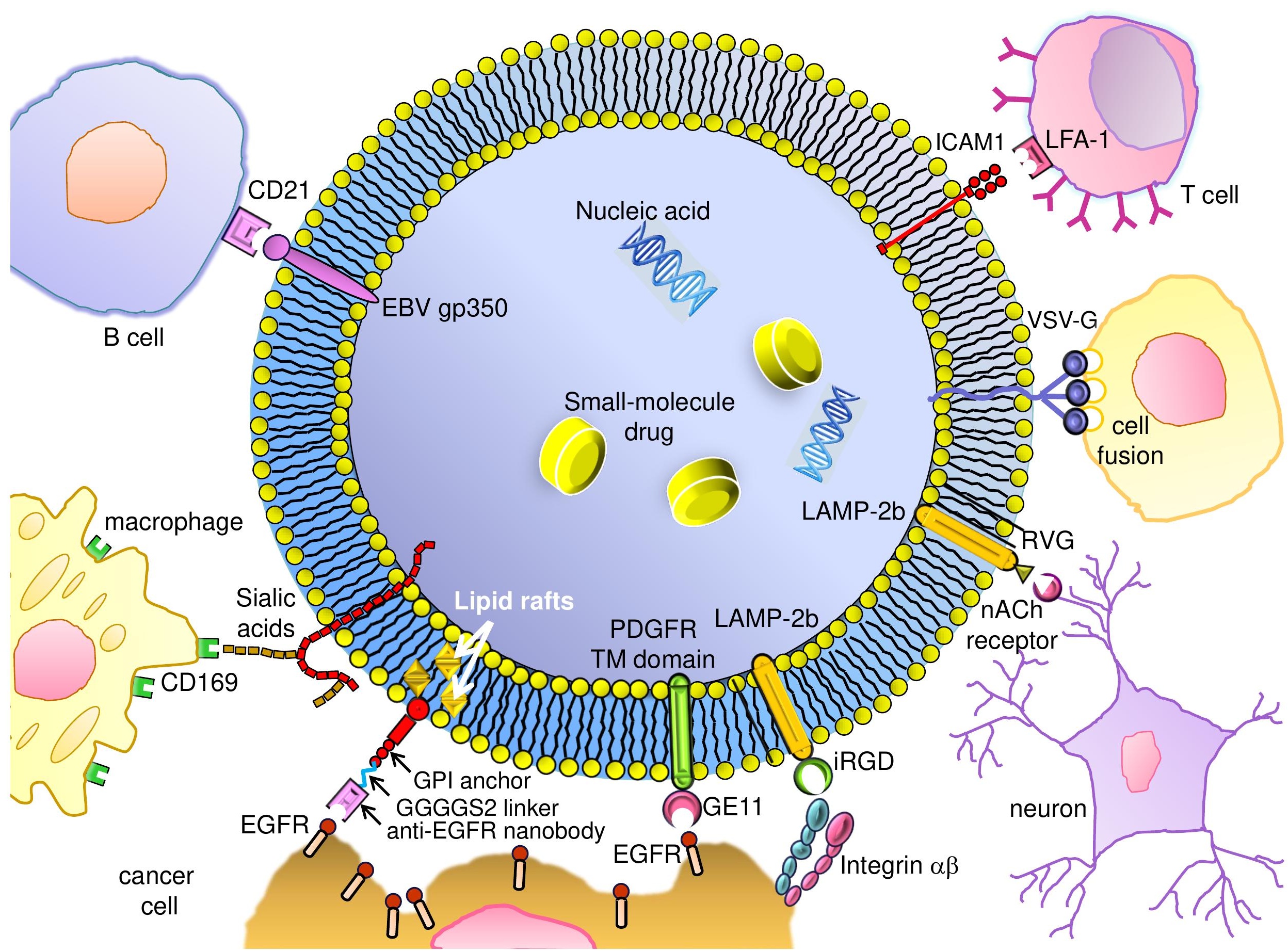

